\title{
Sentinel-2 for mapping the spatio-temporal development of submerged aquatic vegetation at Lake Starnberg (Germany)
}

\author{
Christine FRITZ, ${ }^{1 *}$ Katja KUHWALD, ${ }^{2}$ Thomas SCHNEIDER, ${ }^{1}$ Juergen GEIST, ${ }^{1}$ Natascha OPPELT ${ }^{2}$ \\ ${ }^{1}$ Aquatic Systems Biology Unit, Limnological Research Station Iffeldorf, Department of Ecology and Ecosystem Management, Technical \\ University of Munich, Hofmark 1-3, 82393 Iffeldorf; ${ }^{2}$ Earth Observation and Modelling, Department of Geography, Christian-Albrechts- \\ Universität zu Kiel, Ludewig-Meyn-Str. 14, 24098 Kiel, Germany
}

\begin{abstract}
Submerged aquatic vegetation (SAV) plays an important role in freshwater lake ecosystems. Due to its sensitivity to environmental changes, several SAV species serve as bioindicators for the trophic state of freshwater lakes. Variations in water temperature, light availability and nutrient concentration affect SAV growth and species composition. To monitor the trophic state as required by the European Water Framework Directive (WFD), SAV needs to be monitored regularly. This study analyses the development of macrophyte patches at Lake Starnberg, Germany, by exploring four Sentinel-2A acquired within the main growing season in August and September 2015. Two different methods of littoral bottom coverage assessment are compared, i.e. a semi-empirical method using depth-invariant indices and a physically based, bio-optical method using WASI-2D (Water Colour Simulator). For a precise Sentinel-2 imaging by date and hour, satellite measurements were supported by lake bottom spectra delivered by in situ data-based reflectance models. Both methods identified vegetated and non-vegetated patches in shallow water areas. Furthermore, tall- and meadow-growing SAV growth classes could be differentiated. Both methods revealed similar results when focusing on the identification of sediment and SAV patches $\left(\mathrm{R}^{2}\right.$ from 0.56 to 0.81$)$, but not for a differentiation on SAV class growth level $\left(\mathrm{R}^{2}<0.42\right)$.
\end{abstract}

\section{INTRODUCTION}

Submerged aquatic vegetation (SAV) provides detailed information about the ecology of freshwater lakes (Melzer, 1999). For instance, SAV is a highly suitable and often used bioindicator for trophic state assessments since it mirrors nutrient concentrations, water temperature, water level and water transparency (Skubinna et al., 1995; Melzer, 1999; Penning et al., 2008; Søndergaard et al., 2010; Poikane et al., 2015). Changes in the trophic state induce variations in plant species composition, spatial distribution and extent, onset of SAV growth and senescence (Short and Neckles, 1999; Rooney and Kalff,

Corresponding author: christine.fritz@mytum.de

Key words: Remote sensing; Sentinel-2; submerse aquatic vegetation; inland waters monitoring; depth-invariant index; bio-optical modelling.

Edited by: Mariano Bresciani, CNR-IREA Milan, Italy

Received: 23 April 2018.

Accepted: 3 December 2018.

This work is licensed under a Creative Commons Attribution NonCommercial 4.0 License (CC BY-NC 4.0).

(C) Copyright C. Fritz et al., 2019

Licensee PAGEPress, Italy

J. Limnol., 2019; 78(1): 71-91

DOI: 10.4081/jlimnol.2019.1824
2000; Silva et al., 2008). According to the European Water Framework Directive (WFD) SAV should be mapped every three years (European Commission, 2000). In consideration of the observed strong dynamics in SAV distribution and species composition, Palmer et al. (2015) even recommended more frequent observations. In contrast to conventional SAV monitoring by scientific divers, remote sensing offers a time- and cost-effective alternative to observe seasonal and annual changes in SAV coverage as an indicator of water quality (George, 1997; Malthus and George, 1997; Dekker et al., 2002; Pinnel et al., 2004; Giardino et al., 2007; Yuan and Zhang, 2008; Roessler et al., 2013a; Wolf et al., 2013). In this context, results from Fritz et al. (2017b) suggest that the microclimatic conditions of the respective growing season in conjunction with the related water temperature dynamic may support the differentiation of SAV growth class level. With higher water temperature the development of especially the tall-growing SAV start and collapse earlier. Under such conditions the second level of the meadowgrowing SAV becomes dominant in the reflection spectra, resulting, in some cases, in a second vegetation vitality maximum. In addition, this behaviour, which might become the common one in the course of global warming, might be a key for differentiating more robust invasive species like Elodea nuttallii which do not show such double vitality maximum over the growing season.

Using optical remote sensing data, the spectral information is essential, e.g., the spectral signature of SAV is necessary for analysis of lake bottom surface types. The contributions of SAV and bare sediment for each pixel 
control the intensity of the spectral response. Organic overlay, such as detritus and epiphytes, additionally influences the spectral signature of sediment and SAV (Armstrong, 1993; Fyfe, 2003; Williams et al., 2003; Silva et al., 2008; Wolf et al., 2013). Furthermore, the spectral signature of SAV varies within the growing season. Variations in leaf size and orientation as well as pigment content and ratio lead to changes in shape and intensity of the spectral signature (Fyfe, 2003; Silva et al., 2008; Wolf et al., 2013). Pigment degradation, especially of chlorophyll-a, indicate leaf senescence (Gausman, 1984; Gitelson et al., 2002; Wolf et al., 2013; Fritz et al., 2017b). Especially in case of tall-growing species, pigment decomposition processes accompany structural changes such as the collapse of the canopy. These physiological plant characteristics, however, differ among SAV species. Therefore, Pinnel et al. (2004), Wolf et al. (2013), Fritz et al. (2017b) and others suggested that a method capable to monitor the different phenologic development stages of SAV may provide a valuable key for a refined taxonomic differentiation.

For identifying specific phenology-related characteristics in shallow water areas with remote sensing systems, high spatial, spectral and radiometric resolution data registered at high temporal frequency are mandatory. Analysing remote sensing data in a field-monitoring context additionally requires comparable data sets over time. Therefore, control and correction of external factors influencing the spectral signature of lake bottom types is necessary, i.e. changes in the atmosphere, within the water body and at the atmosphere/water interface. Different strategies exist to consider the attenuation by the water column. The most common approaches belong either to the semi-empirical (Lyzenga, 1978; 1981) or to the biooptical model categories (Heege and Fischer, 2004; Dekker et al., 2011; Giardino et al., 2012; Gege, 2014).

Semi-empirical methods rely on in situ data for littoral bottom type discrimination. Lyzenga (1978, 1981) developed a semi-empirical method based on depthinvariant indices for detecting and distinguishing littoral bottom coverage. Several authors used semi-empirical methods to map SAV with different sensors at different inland waters and at sea. The study of Armstrong (1993) used Landsat Thematic Mapper imagery in combination with field surveys to map seagrass and to estimate its biomass in the shallow water areas at the Bahamas. Brooks et al. (2015) and Shuchman et al. (2013) also used Landsat Thematic Mapper in combination with Multispectral Scanner Imagery time series from the mid1970s to 2012 to investigate SAV patterns (notably Cladophora spec.) at the Laurentian Great Lakes. Manessa et al. (2014) studied the distribution of seagrass and corals of shallow water coral reefs in Indonesia using WorldView2 imagery. Ciraolo et al. (2006) investigated the distribution of seagrass in a coastal lagoon in Italy using the hyperspectral sensor MIVIS (Multispectral Infrared Visible Imaging Sensor). A time series of RapidEye imagery was used to detect seasonal changes of SAV in two freshwater lakes of different trophic state (Lake Starnberg, Roessler et al., 2013a; and Lake Kummerow, Fritz et al., 2017a) in Germany.

Bio-optical model inversion requires information on the scattering and the absorption characteristics of water constituents. The bottom type and coverage determination rely on sample spectra from existing spectral libraries. Several studies have explored different remote sensing data types by using bio-optical models at different inland waters. The changes of SAV patterns at Lake Garda, Italy, was investigated by Giardino et al. (2007) using the hyperspectral sensor MIVIS. Heblinski et al. (2011) used a bio-optical model to investigate the effects of water level changes on SAV structure at Lake Sevan, Armenia, using multi-spectral QuickBird imagery. To monitor invasive SAV, Roessler et al. (2013b) applied the bio-optical model BOMBER (Giardino et al., 2012) on hyperspectral Airborne Prism Experiment (APEX) imagery at Lake Starnberg, Germany. Giardino et al. (2015) used the same model to detect the interaction of suspended particulate matter, SAV and water depth using MIVIS sensor at Lake Trasimeno, Italy.

SAV expansion varies in successive years due to shifts in growing seasons, different water constituents, nutrient load and remobilization processes from lake bottom substrate, which all influence the detectability of SAV (Dekker et al., 2011). To figure out the spatiotemporal change pattern of SAV, however, a short revisiting time and a high spatial and spectral resolution are key requirements for a remote sensing-based lake monitoring. Nowadays, hyperspectral, airborne sensor systems with their high spectral resolution (e.g., APEX, MIVIS) are still unsuitable for a continuous monitoring due to their high costs. The Hyperion mission provided spaceborne hyperspectral data until 2017 which were used for shallow water analysis (Giardino et al., 2007; Lee et al., 2007). Currently, operational, hyperspectral satellite systems are, however, unavailable. The experimental ISS based DLR Earth Sensing Imaging Spectrometer (DESIS), operated since mid 2018, and the hyperspectral sensor PRISMA (PRecursore IperSpettrale della Missione Applicativa, Italian Space Agency) planned for February 2019, may help closing this gap until the experimental EnMAP system is in space, planned for end 2020. As alternative strategy, several authors therefore suggested multi-seasonal images of high spatial resolution multispectral satellite data to compensate the reduced spectral information (Dekker et al., 2011; Roessler et al., 2013a; Palmer et al., 2015; Fritz et al., 2017a). Especially remote sensing systems with 
high revisiting frequencies in combination with large area coverage seem to complement laborious in situ observations of WFD by diver mappings ideally. The expected synergies are the analysis of the expansion and shift in SAV species composition within the growing season in addition with information on the spatiotemporal SAV growth dynamics (Palmer et al., 2015; Fritz et al., 2017b; Dörnhöfer et al., 2018). Especially the multi-spectral Sentinel-2A, available since mid of 2015, provides good preconditions for mapping freshwater lakes and littoral bottom coverage types.

The key aim of this study was to test whether the multi-seasonal observation capability of Sentinel-2A provides sufficient information to support currently employed in situ mappings according to the WFD. Therefore, four Sentinel-2A data sets from August and September 2015 were analysed with the following objectives:

- To investigate whether Sentinel-2 data are suitable for mapping littoral bottom coverage of freshwater lakes.

- To explore the potential of Sentinel-2 for mapping development and expansion of littoral bottom coverage within a SAV growing season.

- To investigate the potential of Sentinel-2 to differentiate SAV on a growth class level.

\section{METHODS}

\section{Study site}

Lake Starnberg $\left(49.9^{\circ} \mathrm{N}, 11.3^{\circ} \mathrm{E}\right)$ is an oligotrophic lake, located in the alpine foreland about $25 \mathrm{~km}$ south of Munich, Germany. With an area of $56.4 \mathrm{~km}^{2}$ and a maximum depth of $127.8 \mathrm{~m}$, Lake Starnberg is the fifth largest lake in Germany (Wöbbecke et al., 2003). Low, groundwater-dominated inflows $\left(3.6 \mathrm{~m}^{3} \cdot \mathrm{s}^{-1}\right)$ of small tributaries as well as low outflow rates $\left(4.5 \mathrm{~m}^{3} \cdot \mathrm{s}^{-1}\right)$ (Melzer et al., 2003) result in a long residence time of water (21 years) (Wöbbecke et al., 2003).

In the shallow water regions, a variety of SAV species colonize the littoral bottom (Fig. 1), making this an ideal study case for comparing alternative mapping approaches. Divers conducted a detailed mapping of SAV on species level on 30 and 31 July 2014 for the western part of Lake Starnberg (WWA Weilheim, 2015) using the five-step scale of frequency after Kohler (1978). The composition of SAV varied at different water depths. At each transect, Characeae, such as Chara contraria and Chara aspera occur mainly in water depths down to $2 \mathrm{~m}$. In the deeper zones, from $4 \mathrm{~m}$ downwards, several species of Characeae (Chara contraria, Chara virgata, Nitellopsis obtusa and
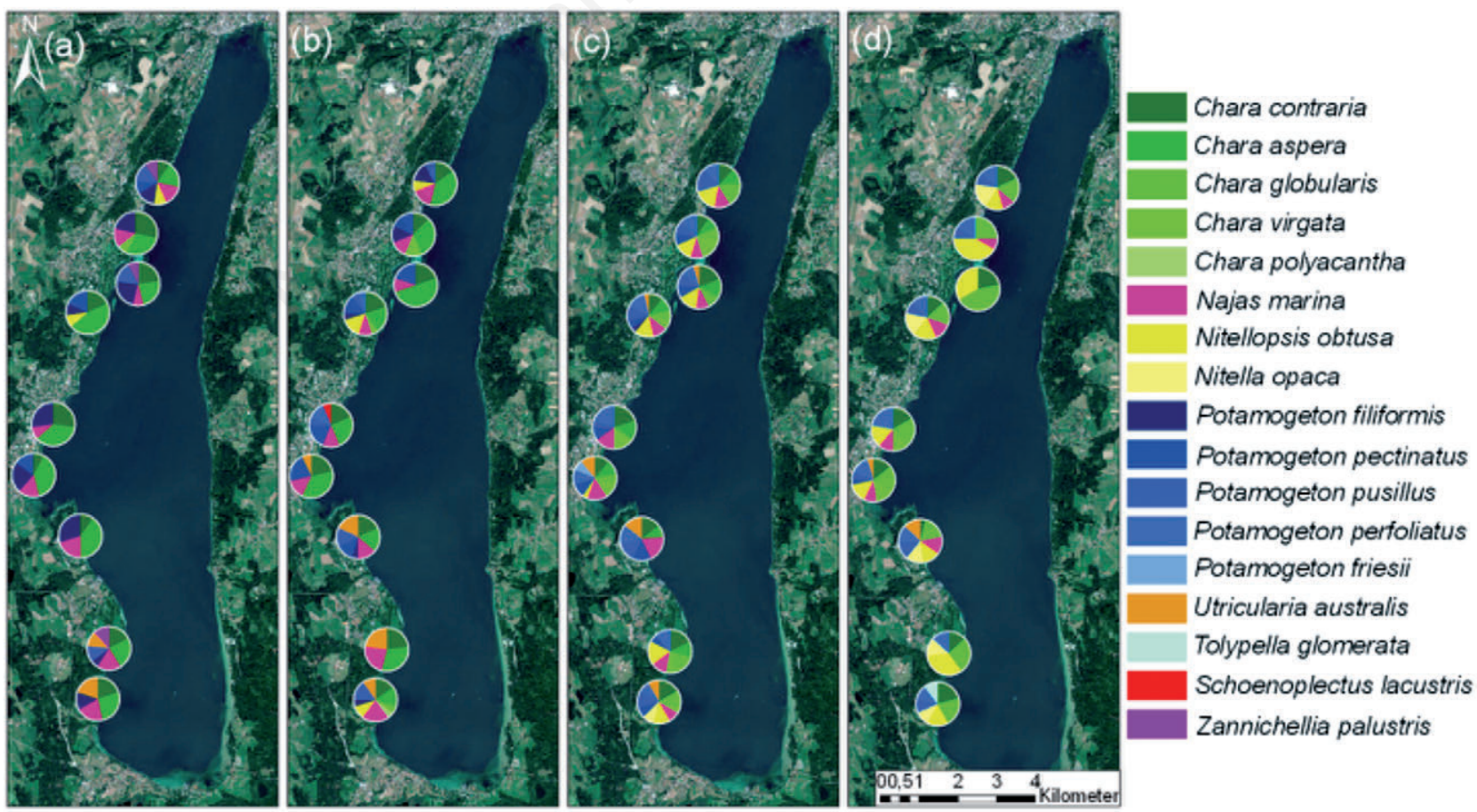

Fig. 1. Distribution of SAV species in different water depths: (a) 0-1 m; (b) 1-2 m; (c) 2-4 m; (d) $>4$ m, as result of the WFD mapping at the western shoreline of Lake Starnberg in 2014; frequency distribution of the species in a five-step scale after Kohler (1978) (background: Sentinel-2A true-colour composite R-G-B: $655 \mathrm{~nm}-560 \mathrm{~nm}-490 \mathrm{~nm}$, acquisition date: 3 August 2015). 
Nitella opaca) predominated. Several pondweed species such as Potamogeton perfoliatus, Potamogeton filiformis and Potamogeton pusillus) were present in all water depths. In our study, Chara spp., Nitellopsis obtusa and Nitella opaca were combined as meadow-growing species, Potamogeton spp. as tall-growing species.

\section{Data collection and processing}

\section{Spectral signature of SAV and sediment}

Both applied approaches, i.e., unmixing bottom coverage based on a depth-invariant index and bio-optical modelling, require the spectral signature of bottom types as an input information, i.e., different SAV species and sediment. Spectro-radiometric in situ measurements of different SAV species with submersible instruments (RAMSES spectroradiometers; spectral range $320 \mathrm{~nm}$ to $950 \mathrm{~nm}$; TriOS, 2018) served as basis for the reflectance models of SAV as developed by Fritz et al. (2017b). A detailed description of the measurement setup, data processing and technical specifications is available in Wolf et al. (2013) and Fritz et al. (2017b). Fritz et al. (2017b) already highlighted spectral variations between different SAV species and demonstrated a species-specific seasonal phenologic development. This information was used to build up species-specific reflectance models (Fritz et al., 2017b) that mirror and visualise the daytime and seasonal, spectral variations of SAV. Using these reflectance models (Fritz et al., 2017b), SAV spectra according to the phenologic development at the date and time of the Sentinel-2A image acquisition were calculated and used as input for the unmixing processes. For unmixing purposes sediment spectra taken before the growing season started were used. The in situ processing chain included a resampling of simulated SAV and sediment spectra (Fritz et al., 2017b) to Sentinel-2A response curves (Dörnhöfer et al., 2016). Afterwards, their depth-invariant indices were calculated (Lyzenga, 1978; 1981). The satellite data processing chain was based on MIP (Modular Inversion and Processing System (Heege and Fischer, 2004; Heege et al., 2014)) atmospherically corrected Sentinel-2A reflectance data sets, which were used to differentiate shallow and deep water areas using the Red Index $(R I)$ (Spitzer and Dirks, 1987). To identify different bottom types, two methods were tested: the method of depthinvariant indices (Lyzenga, 1978; 1981) and the bio-optical method using WASI-2D (Gege, 2014). In both cases, a linear spectral unmixing based on the in situ processed spectra was performed. Fig. 2 schematically illustrates the pathway of data processing.

\section{Data processing of in situ data}

For the Sentinel-2A data set, depth-invariant indices $Y_{i, j}$ of the different bottom types were calculated from spectral bands $i$ and $j$. These indices were assumed to reduce the influence of water constituents to such a level that the investigation of lake bottom types becomes possible. Ten index combinations $\left(Y_{1,2} ; Y_{1,3} ; Y_{1,4} ; Y_{1,5} ; Y_{2,3} ; Y_{2,4} ; Y_{2,5} ; Y_{3,4}\right.$; $Y_{3,5} ; Y_{4,5}$ ) of Sentinel-2A bands 1 to 5 (band $1=443 \mathrm{~nm}$; band $2=490 \mathrm{~nm}$; band $3=560 \mathrm{~nm}$; band $4=665 \mathrm{~nm}$; band $5=705$ $\mathrm{nm})$ were used. The method of Lyzenga $(1978,1981)$ was applied on in situ data assuming that the attenuation coefficients $K_{d}\left(\lambda_{i}\right)$ and $K_{d}\left(\lambda_{j}\right)$ (Maritorena, 1996) account for the influence of present water constituent conditions and the water column itself (equation 1).

$$
\begin{aligned}
& Y_{i, j}=\frac{K_{d}\left(\lambda_{j}\right) \cdot \ln \left(r_{\text {shallow }}\left(\lambda_{i}\right)\right)-K_{d}\left(\lambda_{i}\right) \cdot \ln \left(r_{\text {shallow }}\left(\lambda_{j}\right)\right)}{\sqrt{K_{d}\left(\lambda_{i}\right)^{2}+K_{d}\left(\lambda_{j}\right)^{2}}} \text { (eq. 1) } \\
& i ; j \quad \text { band } i \text {; band } j \text {, where } i<j \\
& K_{d}\left(\lambda_{i}\right) ; K_{d}\left(\lambda_{j}\right) \quad \text { diffuse attenuation coefficients of } \\
& E_{d}(\lambda) \text { at band } i \text { and } j \text {; collected in } \\
& \text { situ and resampled to Sentinel-2A } \\
& \text { response curves (Dörnhöfer et al., } \\
& \text { 2016) } \\
& r_{\text {shallow }}\left(\lambda_{i}\right) ; r_{\text {shallow }}\left(\lambda_{j}\right) \quad \text { shallow water reflectance at band } i \\
& \text { and } j \text {; }
\end{aligned}
$$

The remote sensing reflectance of shallow water areas $\left(r_{\text {shallow }}\right)$ varied for different water depths $(z)$, the remote sensing reflectance of the different bottom types $\left(r_{\text {bottom }}\right)$ and the remote sensing reflectance of the water column $\left(r_{\text {deepwater }}\right)$ (equation 2).

$$
\begin{aligned}
& r_{\text {shallow }}\left(\lambda_{i, j}\right)=r_{\text {bottom }}\left(\lambda_{i, j}\right) \exp ^{-2 K_{d}\left(\lambda_{i, j}\right) z}+r_{\text {deepwater }}\left(\lambda_{i, j}\right)\left(1 \exp ^{-2 K_{d}\left(\lambda_{i, j}\right) z}\right) \\
& \begin{array}{ll}
z & \text { water depth } \\
r_{\text {bottom }}\left(\lambda_{i, j}\right) & \text { littoral bottom reflectance at band }
\end{array} \\
& \begin{aligned}
& r_{\text {bottom }}\left(\lambda_{i, j}\right) \text { littoral bottom reflectance at band } \\
& i, j ; \text { simulated reflectance spectra of }
\end{aligned}
\end{aligned}
$$

\section{Data processing of satellite data}

Sentinel-2A satellite data (processing baseline: 2.04, Tile: UPU) acquired on 3 August 2015, 13 August 2015, 23 August 2015 and 12 September 2015 were atmospherically corrected to remote sensing reflectance $\left(R_{r s}^{0+}=\frac{L_{u}\left(0^{+}\right)}{E_{d}\left(0^{+}\right)}\right)$by EoMAP GmbH \& Co. KG (Seefeld, Germany) using MIP (Heege and Fischer, 2004; Heege et al., 2014). MIP is a physically based, coupled atmospheric-water algorithm correcting the effects of atmosphere and water surfaces (sun glint). In a previous 
study of atmospheric correction algorithms, Dörnhöfer et al. (2016) compared different atmospheric corrections algorithms (i.e., Sen2Cor, ACOLITE and MIP). In this comparison for a Sentinel-2A overpass at Lake Starnberg, MIP performed best $\left(r=0.987, \mathrm{RMSE}=0.002 \mathrm{sr}^{-1}\right)$. That fore we used the result of MIP processing for this study. To distinguish between deep water and shallow water areas the deep water $R I$ (Spitzer and Dirks, 1987) was applied on $R_{r s}^{0+}$ data.

$R I=\frac{R_{r S}^{0+}(665)-R_{r s}^{0+}(665, \infty)}{R_{r s}^{0+}(665)}$

$R_{r s}^{0+}(665)$

$R_{r s}^{0+}(665, \infty)$

remote sensing reflectance value of each pixel in the red

mean red remote sensing reflectance over optically deep water around the deepest point of the lake

Water areas with $R I$ higher than $0.15 \mathrm{sr}^{-1}$ were classified as shallow water and were further investigated. From 2014 to 2017, the mean Secchi disk depth was about
6.4 m (Bavarian Environmental Agency, 2018). To avoid misclassification in optical deep water zones, the areas with more than $8 \mathrm{~m}$ water depths (official bathymetric chart (Bavarian Environmental Agency, 2000)) were excluded from further processing.

\section{Spectral unmixing using depth-invariant indices}

To transfer Sentinel-2A $R_{r s}^{0+}$ data to the same level as in situ measured data, we applied the equation of Lee et al. (1998) (equation 4).

$$
\begin{array}{ll}
R_{r s}^{0+}(\lambda)=\frac{(1-\sigma)\left(1-\sigma_{L}^{-}\right)}{n_{W}^{2}} & \cdot \frac{R_{r s}^{0-}(\lambda)}{1-\sigma^{-} \cdot Q \cdot R_{r s}^{0-}(\lambda)} \\
\sigma ; \sigma_{L}^{-} ; \sigma & \text { reflection factors } \\
Q & \text { ratio of upwelling irradiance to } \\
& \text { upwelling radiance } \\
n_{w}^{2} & \text { squared refractive index of water }
\end{array}
$$

The equation of Lee et al. (1999) can be used to approximate the reflectance from above to beyond the

\section{In situ data processing}

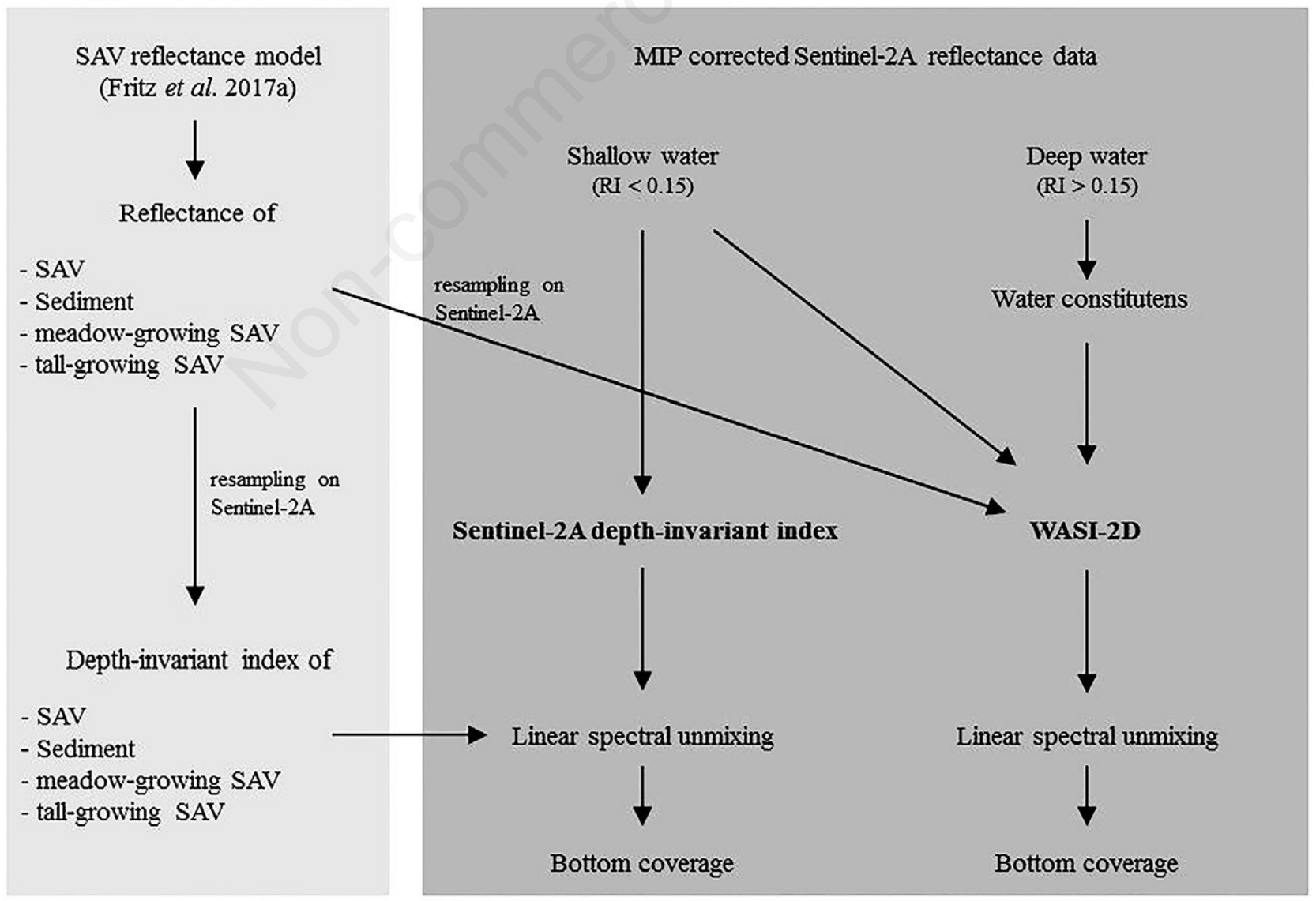

Fig. 2. The pathway of in situ and satellite data processing. 
water surface $\left(\frac{(1-\sigma)\left(1-\sigma_{L}^{-}\right)}{n_{W}^{2}}\right)=0.518 ; \sigma \cdot Q ;($ equation 5$)$.

$R_{r s}^{0-}(\lambda)=\frac{R_{r s}^{0+}(\lambda)}{0.518+1.562 \cdot R_{r s}^{0+}(\lambda)}$

The ten different depth-invariant indices $\left(Y_{i, j}\right)$ were calculated for the subsurface reflectance $\left(Y_{1,2} ; Y_{1,3} ; Y_{1,4}\right.$; $Y_{1,5} ; Y_{2,3} ; Y_{2,4} ; Y_{2,5} ; Y_{3,4} ; Y_{3,5} ; Y_{4,5}$ ) of shallow water regions in the satellite data sets (equation 6). Here, the subsurface reflectances $\left(R_{r s}^{0-}\right)$ of neighbouring bands were related to the diffuse vertical attenuation of the downwelling irradiance $\left(K_{d}\right) . K_{d}$ in combination with the deep water reflectance $\left(R_{r s}^{0-}\left(\lambda_{i, \infty}\right)\right)$ of the respective Seninel-2A data set account for the influence of water column attenuation;

$\left(R_{r s}^{0-}\left(\lambda_{i, \infty}\right)\right)$ originated from a homogenous deep water area and was extracted for each acquisition date separately.

$Y_{i, j}=\frac{K_{d}\left(\lambda_{j}\right) \cdot \ln \left(R_{r s}^{0-}\left(\lambda_{i}\right)-R_{r s}^{0-}\left(\lambda_{i, \infty}\right)\right)-K_{d}\left(\lambda_{i}\right) \cdot \ln \left(R_{r s}^{0-}\left(\lambda_{j}\right)-R_{r s}^{0-}\left(\lambda_{j, \infty}\right)\right)}{\sqrt{K_{d}\left(\lambda_{i}\right)^{2}+K_{d}\left(\lambda_{j}\right)^{2}}}$

$i ; j$

$K_{d}\left(\lambda_{i}\right) ; K_{d}\left(\lambda_{j}\right)$

band $i$; band $j$, where $i<j$

(eq

Diffuse attenuation coefficients of $E_{d}(\lambda)$ at band $i$ and $j$

$R_{r s}^{0-}\left(\lambda_{i}\right) ; R_{r s}^{0-}\left(\lambda_{j}\right) \quad$ remote sensing reflectance at band $i$ and $j$ of each pixel

$R_{r s}^{0-}\left(\lambda_{i, \infty}\right) ; R_{r s}^{0-}\left(\lambda_{j, \infty}\right)$ mean deep water remote sensing reflectance at band $i$ and $j$

The calculated $Y_{i, j}$ data set was the input for a linear spectral unmixing process performed with Sentinel Application Platform SNAP (ver. 4.0). The $Y_{i, j}$ index values of the different littoral bottom types represented the spectral endmembers. Linear spectral unmixing varies the share of the considered spectral endmembers at a pixel's signature assuming a linear contribution. Here, we assume that the unmixed share of an endmember $\left(f_{i_{-}}\right)$ normalized between 0 and 1 , represents the relative abundance (bottom coverage) of a littoral bottom type.

Based on these normalized bottom coverage data we started two independent classification runs. To distinguish between areas of sediment and SAV, we used two bottom types. This run was performed to separate vegetated areas (independent on their growth height level) from bare sediment patches (sediment and SAV). To differentiate the vegetated areas into tall- and meadow-growing SAV classes, we used three bottom types. This run focused on the distribution of SAV growth types (sediment, tallgrowing SAV and meadow-growing SAV). The input spectra with different sun elevations were simulated with the reflectance model (Fritz et al., 2017b) according to the respective overpass time of the satellite.

\section{Spectral unmixing using WASI-2D}

WASI-2D is a freely available software tool, which enables the retrieval of water constituents, bottom characteristics and water depths by inversely modelling atmospherically corrected multispectral or hyperspectral imagery (Gege, 2014). WASI-2D models the $R_{r s}^{0+}$ using physically based equations, measured or modelled constants and parameters. Some parameters, i.e., fit parameters, can be varied during modelling. In shallow water, WASI-2D considers the spectral influence of the water depth, fractional contribution from bottom reflectance (e.g., different shares of pure reflectance from sediment and SAV) and light absorbing (chlorophyll-a (CHL), coloured dissolved organic matter (CDOM) and backscattering (TSM) water constituents (technical details and specific equations in Gege, 2014). For this study, fit criterions were the water depth, bottom types and fractions of bottom coverage.

To avoid overfitting of the model, concentrations of CHL, TSM and CDOM (at $440 \mathrm{~nm}$ ) were set constant. To obtain reasonable values for the model parameters we first retrieved water constituent concentrations (CHL, CDOM, TSM and the CDOM slope factor $\mathrm{S}_{\mathrm{CDOM}}$ ) in deep water of each acquisition date with a setting as described in Dörnhöfer et al. (2016) (Tab. 1).

We used the arithmetic mean of deep water results as constant parameter values for shallow water inversion. Water depth was considered as a fit parameter, which could vary between 0.1 and $8.0 \mathrm{~m}$. WASI-2D calculates the reflectance from the bottom $\left(R^{b}(\lambda)\right)$ as the sum of linearly mixing reflectance from different bottom types (equation 7).

Tab. 1. Water constituent concentrations over optically deep water for Sentinel-2A acquisition dates, retrieved with a setting as described in Dörnhöfer et al. (2016).

\begin{tabular}{lcccc} 
Parameter & 3 Aug 2015 & 13 Aug 2015 & 23 Aug 2015 & 12 Sep 2015 \\
CHL $\left(\mathrm{mg} \cdot \mathrm{m}^{-3}\right)$ & 0.97 & 3.45 & 2.86 & 0.5 \\
\hline $\operatorname{TSM}\left(\mathrm{g} \cdot \mathrm{m}^{-3}\right)$ & 1.25 & 3.56 & 2.38 & 2.18 \\
\hline $\operatorname{CDOM}(440)\left(\mathrm{m}^{-1}\right)$ & 0.183 & 0.182 & 0.227 & 0.398 \\
\hline SCDOM $\left(\mathrm{nm}^{-1}\right)$ & 0.0163 & 0.0163 & 0.0093 & 0.0065 \\
\hline
\end{tabular}




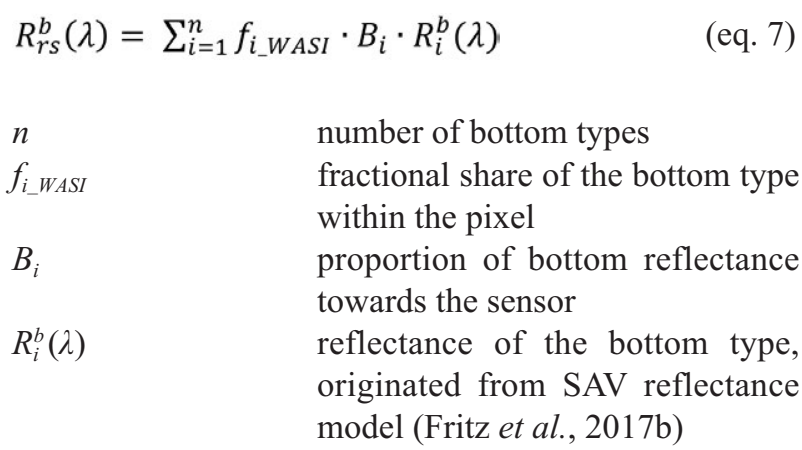

After resampling the spectral database of WASI-2D to the Sentinel-2A spectral response curves as described in Dörnhöfer et al. (2016), WASI-2D inversely models the $R_{r s}^{0+}$ and compares modelled and Sentinel-2A $R_{r s}^{0+}$ spectra for each pixel. The model then varies the fit parameters in a predefined range until modelled and satellite $R_{r s}^{0+}$ match a similarity criterion or, if no perfect match is feasible, a predefined maximum number of iterations is achieved.

To unmix the spectra of bottom constituents, the proportion of bottom reflectance towards the sensor was assumed to be angle-independent, i.e. Lambertian surfaces $\left(\mathrm{B}_{\mathrm{i}}=1 / \pi \mathrm{sr}^{-1}\right)$. For each acquisition date, we fitted $f_{i \_ \text {WASI }}$ to linearly unmix bottom types while considering variable water depths and a constant contribution of water constituents to the reflectance. $f_{i \_ \text {WASI }}$ was normalized to a range between 0 and 1 . Similar to the unmixing approach based on the depth-invariant index, we conducted model runs with two $(n=2$ : sediment and $\mathrm{SAV})$ and three $(\mathrm{n}=3$ : sediment, tall-growing SAV class, meadow-growing SAV class) bottom types. To reduce the influence of sun glint (not corrected by MIP) we additionally varied the share of directly reflected radiance (see Dörnhöfer et al., 2016).

To compare the results of both methods, we conducted a linear regression analysis between obtained and normalised endmember shares, $f_{i_{-} Y}$ and $f_{i_{-} \text {WASI }}$, using the software R (R Core Team, 2017, ver.3.4.2). For each Sentinel-2A data set, both parameters were compared in scatterplots based on the entire shallow water. Calculation of the coefficient of determination, $R^{2}$, supported assessing the similarities and differences between the resulting littoral bottom coverage of both approaches.

\section{RESULTS}

\section{Seasonal spectral variation within the growing season}

The spectra of the three investigated littoral bottom types (sediment, meadow-growing SAV class and tallgrowing SAV class) were consistently different, following bimonthly modelling with the SAV reflectance models (Fritz et al., 2017b) for the $1^{\text {st }}$ and $15^{\text {th }}$ of June, July, August and September (Fig. 3). Resampled to Sentinel-2A bands, the spectral response of the surface types also differed clearly in spectral shape and intensity at each of the observed dates within the growing season (Fig. 4) Overall, while the intensity of the remote sensing reflectance remained low in the visible wavelength regions $(400 \mathrm{~nm}$ to $700 \mathrm{~nm}$ ), it increased strongly towards the near infrared region (>700 nm, Figs. 3 and 4). In the visible wavelength region, the reflectance of sediment was the highest. Reflectance of meadow- and tall-growing SAV was similar in spectral shape, but differed in intensity. The reflectance intensity of meadow-growing SAV was slightly higher than the intensity of tall-growing SAV.

\section{Spectral unmixing of shallow water areas using depth-invariant indices}

The depth-invariant index analysis of the littoral bottom types at the test sites Roseninsel, Karpfenwinkel and Seeshaupt based on the pre-processed Sentinel-2A data sets. It revealed a different spatial extension of SAV (green) and sediment (red) patches (Fig. 5) and a different SAV class composition (sediment (red), meadow-growing (green) and tall-growing (blue) SAV, Fig. 6) for the investigated dates. The spatial distribution of sediment and SAV classes changed during the growing season. The spatial extension of shallow water areas depended on the index, which may differ for each Sentinel-2A data set.

At the test site Roseninsel, the first index run classified large sediment and mixed sediment dominated patches (Fig. 5, Tab. 2). Mixed SAV-dominated patches were identified at the western shoreline of Lake Starnberg and at the south-eastern part of the island Roseninsel. For all Sentinel-2A acquisition dates, the sediment-dominated patches were similarly large and clearly zoned from vegetated areas. For the test site Karpfenwinkel, large sediment-dominated patches were classified in the centre at the beginning of August. This clear spatial distinction between sediment and SAV areas decreased during August, resulting in a large mixed area. On 12 September, only a small band at the shoreline was classified as shallow water area. At the test site Seeshaupt, the classified littoral bottom coverages changed solely in midSeptember. The first index run further identified large sediment-dominated areas in the south-western part of this test site (up to $45.59 \%$ ), while SAV patches were tagged in the south-eastern part near the shoreline. On 12 September, the former sediment area at the eastern shoreline was classified as mixed area $(75.70 \%)$.

The results of the second run revealed more details on the distribution of SAV growth types in the mixed and dense SAV patches (Fig. 6, Tab. 3). On 3, 13 and 23 August, the majority of the shallow water area at the test site Roseninsel was assigned as sediment, while small patches of tall- (up to 7.68\%) and meadow-growing (up to 4.99\%) 
Tab. 2. Areas classified for each littoral bottom type using depth-invariant index and the two-bottom-type approach (sediment $<0.3$, mixed sediment dominated: 0.3-0.5; mixed SAV dominated: 0.5-0.7; dense SAV >0.7).

\begin{tabular}{|c|c|c|c|c|c|}
\hline \multicolumn{3}{|c|}{ Two-bottom-type approach } & \multicolumn{3}{|c|}{ Depth-invariant index data (\%) } \\
\hline Test site & Littoral bottom type & 3 Aug 2015 & 13 Aug 2015 & 23 Aug 2015 & 12 Sep 2015 \\
\hline \multirow[t]{4}{*}{ Roseninsel } & Sediment & 0.73 & 64.07 & 76.43 & 77.46 \\
\hline & Mixed sediment dominated & 56.69 & 35.93 & 23.06 & 21.20 \\
\hline & Mixed SAV dominated & 42.43 & 0 & 0.51 & 1.34 \\
\hline & Dense SAV & 0.15 & 0 & 0 & 0 \\
\hline \multirow[t]{4}{*}{ Karpfenwinkel } & Sediment & 0 & 14.69 & 25.34 & 2.50 \\
\hline & Mixed sediment dominated & 13.23 & 81.95 & 63.43 & 65.25 \\
\hline & Mixed SAV dominated & 74.16 & 3.36 & 10.95 & 32.00 \\
\hline & Dense SAV & 12.61 & 0 & 0.28 & 0.25 \\
\hline \multirow[t]{4}{*}{ Seeshaupt } & Sediment & 0 & 32.34 & 45.59 & 20.55 \\
\hline & Mixed sediment dominated & 14.95 & 60.36 & 48.99 & 61.68 \\
\hline & Mixed SAV dominated & 77.86 & 5.89 & 4.67 & 14.02 \\
\hline & Dense SAV & 7.19 & 1.42 & 0.76 & 3.75 \\
\hline
\end{tabular}

SAV, submerged aquatic vegetation.
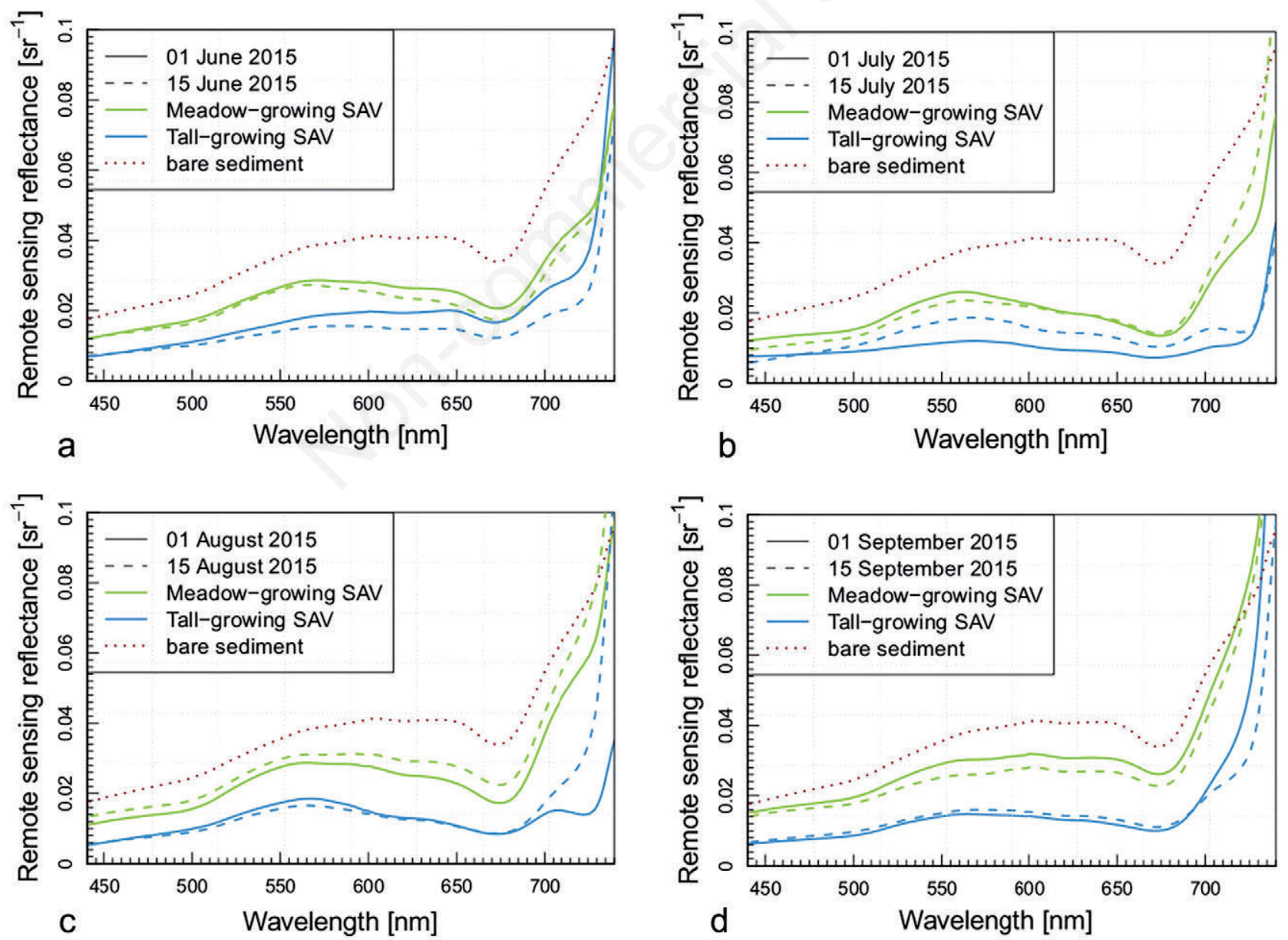

Fig. 3. Remote sensing reflectance of meadow- and tall-growing SAV classes, simulated with the reflectance model, for the $1^{\text {st }}$ and $15^{\text {th }}$ of June (a), July (b), August (c), and September (d). The sediment spectrum was constant for each day. 
SAV were located at the south-eastern part of the island and a narrow stripe along the shoreline was classified as meadow-growing SAV. On 12 September, the situation changed and nearly the entire shallow water area was classified as a mixture of sediment and tall-growing SAV (99.45\%). On 3, 13 and 23 August, a large sediment mixed area patch dominated the centre of the test Karpfenwinkel. Meadow-growing SAV populated the shallow areas in the south (up to 14.57\%), while tall-growing SAV predominated in deeper areas in the north (up to $37.10 \%$ ). During August, however, the patches of tall-growing SAV increased (from $21.27 \%$ to $37.10 \%$ ). On 12 September, only a narrow stripe along the shoreline was detected as shallow water, dominated by a mixture of sediment and tallgrowing SAV. On 3, 13 and 23 August, meadow-growing SAV were situated in the south-eastern near the shoreline part and sediment patches in the south-western part of test site Seeshaupt. Tall-growing SAV were located in deeper zones: the eastern shoreline was classified as a mixture of sediment and meadow-growing SAV. On 12 September, the entire shallow water area was classified as a mixture of sediment, tall- and meadow-growing vegetation dominating the entire shallow water area.

\section{Spectral unmixing of shallow water areas using WASI-2D}

WASI-2D based unmixing was also carried out for the test sites Roseninsel, Karpfenwinkel and Seeshaupt. Again, two unmixing runs were conducted, i.e. one to differ between sediment (red) and SAV (green) (Fig. 7) and one to distinguish sediment (red), meadow-growing (green) and tall-growing (blue) SAV (Fig. 8).

At the test site Roseninsel, the first run revealed large sediment patches around the island Roseninsel for all Sentinel-2A acquisition dates (Fig. 7, Tab. 4). On 3 and 13 August, towards deeper water mixed areas dominate, followed by patches classified as dense SAV. On 23
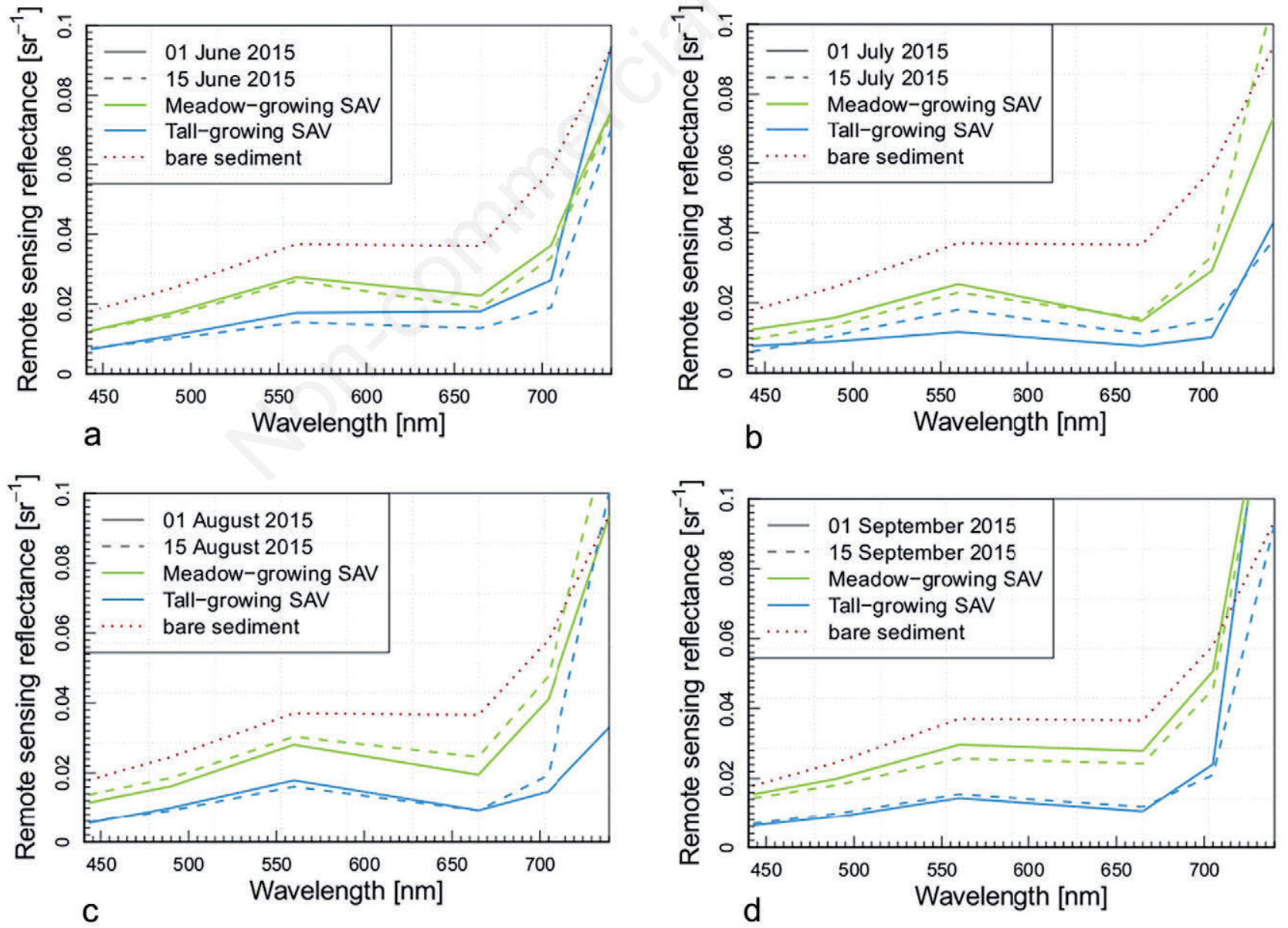

Fig. 4. Remote sensing reflectance of meadow- and tall-growing SAV classes, simulated with the reflectance model and resampled on Sentinel-2A bands, for the $1^{\text {st }}$ and $15^{\text {th }}$ of June (a), July (b), August (c), and September (d). The sediment spectrum was constant for each day. 
August and 12 September, the area classified as sediment increased $(80.28 \%)$ and SAV patches almost disappeared $(2.82 \%)$. At the test site Karpfenwinkel, SAV-dominated patches were covering almost the complete shallow water area on 3,13 and 23 August (up to $76.89 \%$ ); sediment and patches of mixed bottom types were located in the north and in the southeast. The sediment-dominated patches increased noticeably on 23 August (60.93\%). On 12 September, only a narrow stripe at the shoreline was classified as shallow water, which was dominated by sediment and mixed areas. At the test site Seeshaupt, sediment patches and mixed areas were detected in the western part and at the eastern shoreline for all Sentinel-
$2 \mathrm{~A}$ acquisition dates. On August 3, the majority of the shallow water area in the south was classified as dense SAV (17.22\%). This SAV patch decreased on August 23 $(3.96 \%)$ and September $12(0.90 \%)$, resulting in an increase of sediment-dominated patches $(90.75 \%)$. The pattern was similar on September12, although the detected shallow water area was considerably smaller.

For the test site Roseninsel, the results of the second run (Fig. 8, Tab. 5) revealed large sediment areas around the island (up to $69.42 \%$ ), followed by patches of tallgrowing SAV in deeper water on 3, 13 and 23 of August. Small isolated patches of meadow-growing SAV (up to $6.29 \%$ ) occurred between tall-growing areas (up to

Tab. 3. Areas classified for each littoral bottom type using depth-invariant index and the three-bottom-type approach.

\begin{tabular}{|c|c|c|c|c|c|}
\hline \multicolumn{3}{|c|}{ Three-bottom-type approach } & \multicolumn{3}{|c|}{ Depth-invariant index data (\%) } \\
\hline Test site & Littoral bottom type & 3 Aug 2015 & 13 Aug 2015 & 23 Aug 2015 & $12 \operatorname{Sep} 2015$ \\
\hline \multirow[t]{4}{*}{ Roseninsel } & Sediment & 56.79 & 4.36 & 10.67 & 0.95 \\
\hline & Meadow-growing classes & 4.99 & 1.22 & 1.13 & 0.55 \\
\hline & Tall-growing classes & 7.68 & 5.14 & 4.66 & 12.27 \\
\hline & Mixed area & 30.54 & 89.29 & 83.54 & 86.22 \\
\hline \multirow[t]{4}{*}{ Karpfenwinkel } & Sediment & 22.14 & 3.77 & 2.18 & 0.50 \\
\hline & Meadow-growing classes & 14.57 & 6.94 & 2.12 & 9.00 \\
\hline & Tall-growing classes & 21.27 & 35.99 & 37.10 & 21.25 \\
\hline & Mixed area & 42.02 & 53.30 & 58.60 & 69.25 \\
\hline \multirow[t]{4}{*}{ Seeshaupt } & Sediment & 37.91 & 9.34 & 7.30 & 0.05 \\
\hline & Meadow-growing classes & 10.11 & 5.10 & 2.33 & 6.33 \\
\hline & Tall-growing classes & 20.85 & 25.47 & 16.43 & 15.46 \\
\hline & Mixed area & 31.13 & 60.08 & 73.95 & 78.16 \\
\hline
\end{tabular}

Tab. 4. Areas classified for each littoral bottom type using bio-optical modelling and the two-bottom-type approach (sediment $<0.3$, mixed sediment dominated: 0.3-0.5; mixed SAV dominated: 0.5-0.7; dense SAV >0.7).

\begin{tabular}{|c|c|c|c|c|c|}
\hline \multicolumn{3}{|c|}{ Two-bottom-type approach } & \multicolumn{3}{|c|}{ Bio-optical modelling data (\%) } \\
\hline Test site & Littoral bottom type & 3 Aug 2015 & 13 Aug 2015 & 23 Aug 2015 & 12 Sep 2015 \\
\hline \multirow[t]{4}{*}{ Roseninsel } & Sediment & 51.24 & 50.73 & 80.28 & 68.07 \\
\hline & Mixed sediment dominated & 18.27 & 34.74 & 12.25 & 26.05 \\
\hline & Mixed SAV dominated & 23.95 & 14.53 & 4.65 & 5.04 \\
\hline & Dense SAV & 6.54 & 0.00 & 2.82 & 0.84 \\
\hline \multirow[t]{4}{*}{ Karpfenwinkel } & Sediment & 3.79 & 7.09 & 30.66 & 45.31 \\
\hline & Mixed sediment dominated & 19.32 & 48.57 & 30.27 & 37.32 \\
\hline & Mixed SAV dominated & 49.72 & 44.25 & 33.11 & 17.37 \\
\hline & Dense SAV & 27.18 & 0.08 & 5.96 & 0.00 \\
\hline \multirow[t]{4}{*}{ Seeshaupt } & Sediment & 21.61 & 30.97 & 55.64 & 74.64 \\
\hline & Mixed sediment dominated & 22.06 & 34.28 & 29.38 & 16.10 \\
\hline & Mixed SAV dominated & 39.11 & 31.30 & 11.02 & 8.35 \\
\hline & Dense SAV & 17.22 & 3.45 & 3.96 & 0.90 \\
\hline
\end{tabular}


23.31\%). On August 23, however, the area classified as sediment increased strongly $(69.42 \%)$, while tall- $(8.33 \%)$ and meadow-growing $(2.45 \%)$ patches decreased. At the test site Karpfenwinkel large patches of tall-growing SAV were classified in the centre and meadow-growing SAV and sediment patches in the south at the beginning of August. On August 13, a mixture of sediment and meadow-growing SAV with isolated patches of tall- growing SAV $(7.43 \%)$ covered the shallow water area. These sediment patches (23.73\%) increased on August 23, framed by tall-growing SAV. Meadow-growing SAV were located in the south of the test site. In September, sediment dominated the narrow stripe along the shoreline classified as shallow water. At the test site Seeshaupt, large sediment areas were classified in the south-western part and at the eastern shoreline for all Sentinel-2A

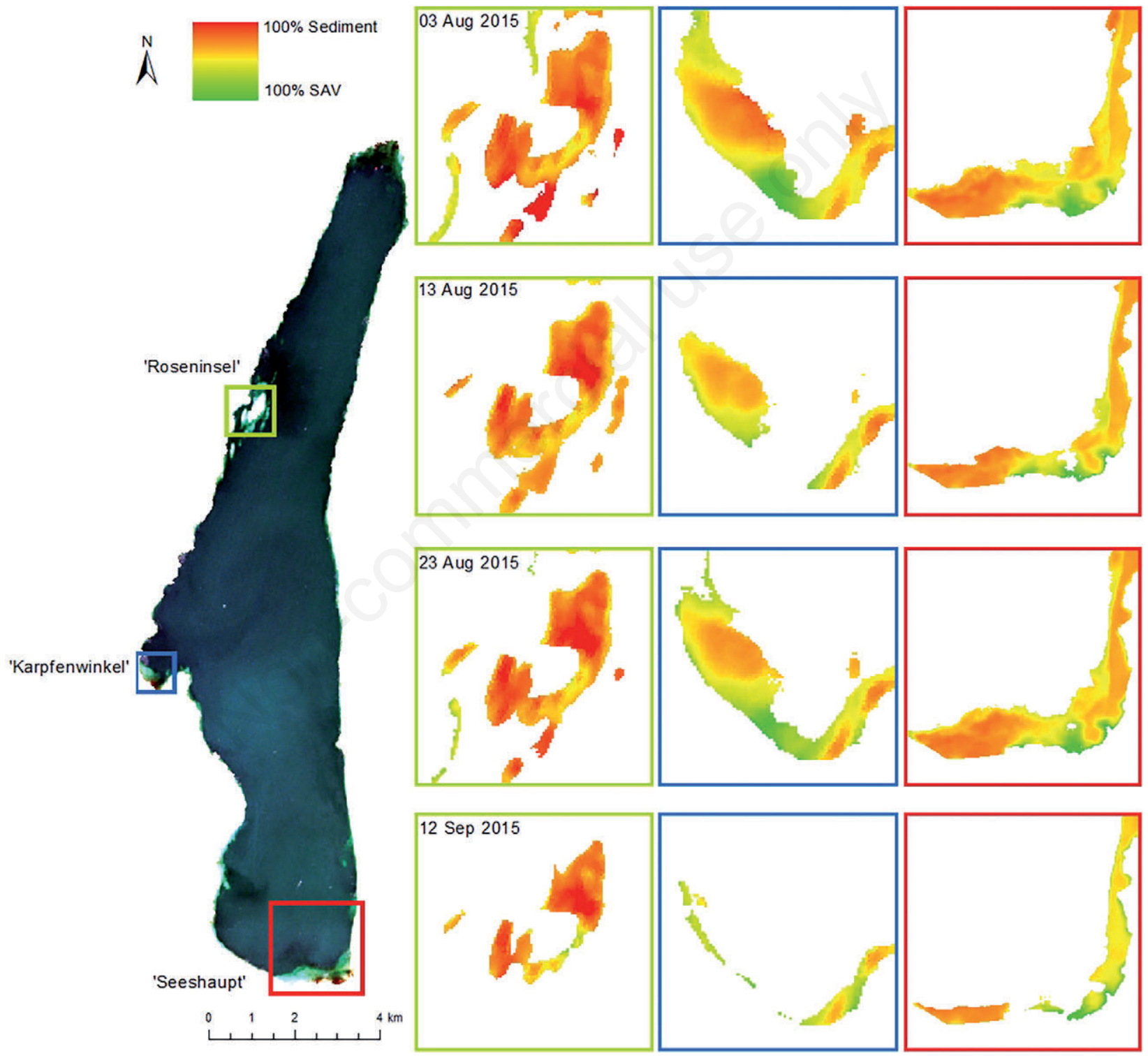

Fig. 5. Littoral bottom coverage of the investigated shallow water areas at Lake Starnberg illustrated after the linear spectral unmixing using the depth-invariant indices on 3 August 2015, 13 August 2015, 23 August 2015 and 12 September 2015 (Sentinel-2A true-colour composite R-G-B: $665 \mathrm{~nm}-560 \mathrm{~nm}-490 \mathrm{~nm}$, acquisition date: 3 August 2015; left). The boxes represent the investigated shallow water areas from left to right: 'Roseninsel' (green box), 'Karpfenwinkel' (blue box) and 'Seeshaupt' (red box). The linear spectral unmixing of 2 bottom types displays $100 \%$ bare sediment areas in red and 100\% dense vegetated areas in green, mixed areas in yellow. Land and deep water areas are masked. 
acquisition dates. At the beginning of August, large areas of tall-growing SAV (22.58\%) with isolated small patches of meadow-growing SAV dominated the centre of this test site. On 13 and 23 of August, the areas of tall-growing SAV strongly decreased; sediment dominated the shoreline, meadow-growing SAV the deeper water. In September most of the shallow water area was assigned as sediment $(68.83 \%)$.

\section{Analysing the results of the spectral unmixing of both methods}

To compare the results of both methods, a scatterplot with linear regression lines was performed for both methods for each bottom type and acquisition date. Fig. 9 shows a comparison of the two-bottom-type approach (grey) and of the three-bottom-type approach (red). Both

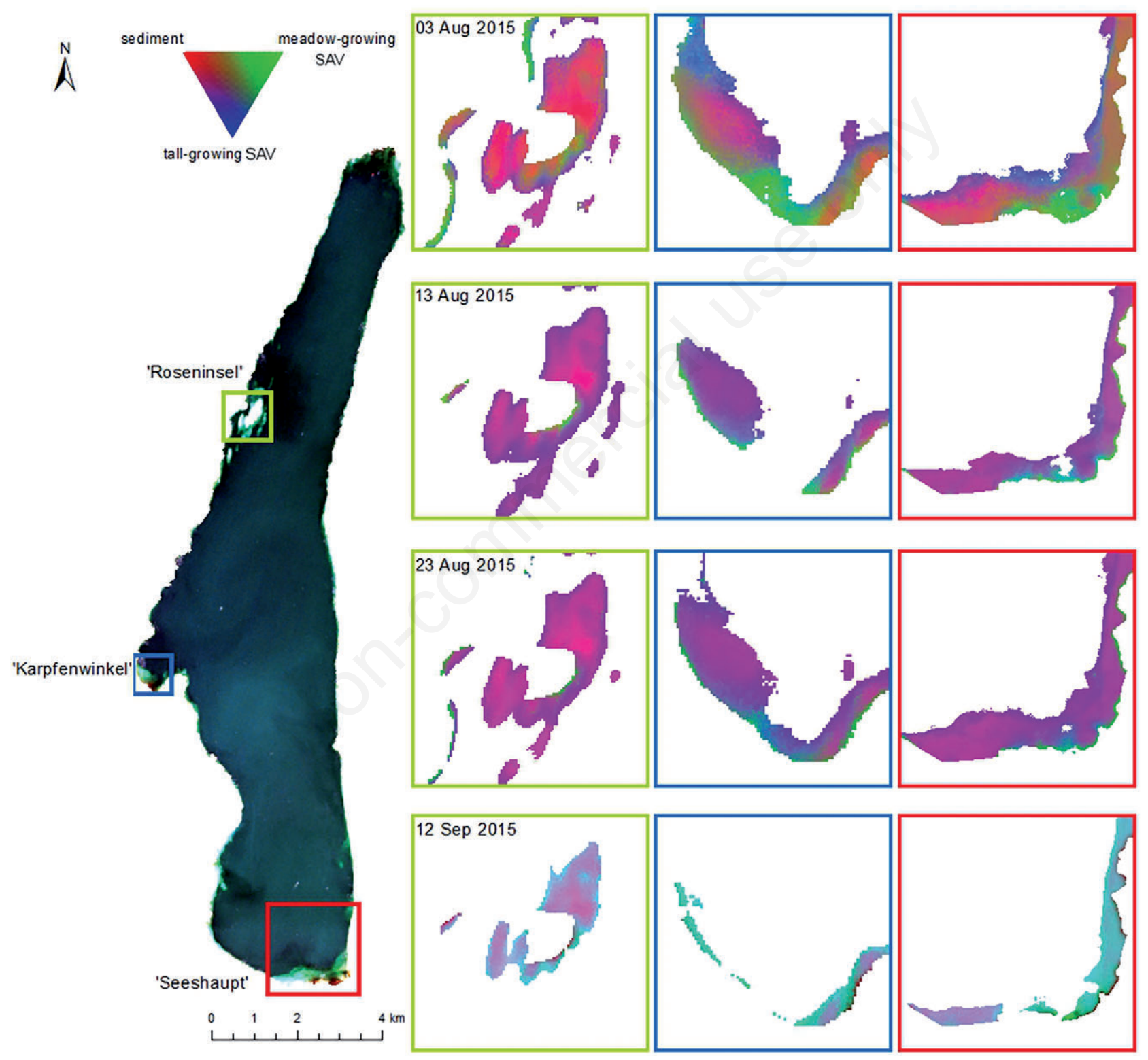

Fig. 6. Littoral bottom coverage of the investigated shallow water areas at Lake Starnberg illustrated after the linear spectral unmixing using the depth-invariant indices on 3 August 2015, 13 August 2015, 23 August 2015 and 12 September 2015 (Sentinel-2A true-colour composite R-G-B: 665 nm-560nm-490nm, acquisition date: 3 August 2015; left). The boxes represent the investigated shallow water areas from left to right: 'Roseninsel' (green box), 'Karpfenwinkel' (blue box) and 'Seeshaupt' (red box). The result of 3 bottom types displays areas of bare sediment (red), meadow-growing plant SAV classes (green) and tall-growing plant SAV classes (blue). Land and deep water areas are masked. 
approaches showed a correlation, though the results of two-bottom-types approach were less scattered. The results of both approaches differentiating between two littoral bottom types (Figs. 5 and 7) also emphasized visually a similar spatial distribution of sediment and dense SAV patches. For example, at the test site Roseninsel, both approaches showed predominating sediment (red) areas for all acquisition dates. When using the depth-invariant index (Fig. 5), the remaining patches were mixed areas (yellow and orange), while WASI-2D classified those patches as mixed (yellow) and dense SAV areas (green) (Fig. 7).

The results for meadow-growing (green) and tallgrowing (blue) SAV indicated widely scattered values (Fig. 10), with low coefficients of determination $\left(\mathrm{R}^{2}\right.$, see Tab. 6). The highest coefficients of determination were achieved for two-bottom-type approach ( $\mathrm{R}^{2}$ up to 0.81$)$. The $\mathrm{R}^{2}$ values of the results of the three-bottom-type approach were consistently lower ( $\mathrm{R}^{2}$ up to 0.42$)$. Meadow- and tall-growing SAV correlations obtained the lowest $\mathrm{R}^{2}$ values $\left(\mathrm{R}^{2}=0.007\right.$ and $\left.\mathrm{R}^{2}=0.003\right)$. The results of the three-bottom-type approach (Figs. 6 and 8) demonstrated a similar spatial distribution of sediment and SAV patches, but showed no comparable spatial distribution for SAV on class growth level. For example, for the test site Karpfenwinkel, the results of both methods completely differed on 3 and 13 of August: WASI-2D derived a large patch of tall-growing SAV whereas the depth-invariant index detected sediment and mixed areas of sediment and meadow-growing SAV.

\section{DISCUSSION}

The key aim of this study was to investigate the performance of a Sentinel-2 multi-seasonal time-series in providing information of in situ mappings according to the WFD. For investigating the littoral bottom coverage mapping capability in shallow water areas of Lake Starnberg, two established methods were applied, i.e. the depth-invariant index and bio-optical modelling with WASI-2D. The second objective was to analyse whether a time series of Sentinel-2 data allows a reconstruction of the spatio-temporal dynamics of littoral bottom coverage within a SAV growing season. The third objective was to investigate whether Sentinel-2 data provide sufficient spectral detail to allow a differentiation on class growth level (meadow and tall-growing SAV).

Tab. 5. Areas classified for each littoral bottom type using bio-optical modelling and the three-bottom-type approach.

\begin{tabular}{|c|c|c|c|c|c|}
\hline \multicolumn{2}{|c|}{ Three-bottom-type approach } & \multicolumn{4}{|c|}{ Bio-optical modelling data (\%) } \\
\hline Test site & Littoral bottom type & 3 Aug 2015 & 13 Aug 2015 & 23 Aug 2015 & $12 \operatorname{Sep} 2015$ \\
\hline \multirow[t]{4}{*}{ Roseninsel } & Sediment & 42.22 & 43.65 & 69.42 & 90.96 \\
\hline & Meadow-growing classes & 6.29 & 2.52 & 2.45 & 0.15 \\
\hline & Tall-growing classes & 23.31 & 8.73 & 8.33 & 2.38 \\
\hline & Mixed area & 28.18 & 45.10 & 19.80 & 6.51 \\
\hline \multirow[t]{4}{*}{ Karpfenwinkel } & Sediment & 3.64 & 6.02 & 23.73 & 38.50 \\
\hline & Meadow-growing classes & 3.02 & 4.90 & 4.90 & 3.29 \\
\hline & Tall-growing classes & 32.17 & 7.43 & 7.47 & 15.02 \\
\hline & Mixed area & 61.17 & 81.65 & 63.90 & 43.19 \\
\hline \multirow[t]{4}{*}{ Seeshaupt } & Sediment & 19.07 & 28.50 & 48.66 & 68.83 \\
\hline & Meadow-growing classes & 0.87 & 12.30 & 11.83 & 1.04 \\
\hline & Tall-growing classes & 22.58 & 2.00 & 1.90 & 0.35 \\
\hline & Mixed area & 57.48 & 57.20 & 37.61 & 29.78 \\
\hline
\end{tabular}

Tab. 6. $\mathrm{R}^{2}$ values for the different littoral bottom types for each acquisition date.

\begin{tabular}{lcccc} 
Littoral bottom type & 3 Aug 2015 & 13 Aug 2015 & 23 Aug 2015 & 12 Sep 2015 \\
Sediment (2 bottom types) & 0.56 & 0.66 & 0.81 & 0.79 \\
\hline Sediment (3 bottom types) & 0.42 & 0.27 & 0.31 & 0.24 \\
\hline Meadow-growing classes & 0.06 & 0.007 & 0.05 & 0.11 \\
\hline Tall-growing classes & 0.04 & 0.003 & 0.18 & 0.39 \\
\hline
\end{tabular}




\section{Differentiation and seasonal changes of littoral bottom coverage}

In our study both methods, i.e. the depth-invariant index and WASI-2D, were able to retrieve bottom substrate maps based on two bottom types i.e., SAV and sediment, which indicates the potential suitability of Sentinel-2A for monitoring littoral bottom coverage. Both approaches detected similar spatial patterns and distributions of SAV and sediment (Figs. 5 and 7, Tabs. 2 and 4). Sediment predominates shallow water zones exposed to wind and waves (e.g., the test site Roseninsel) and shipping traffic (e.g. the western part of test site Seeshaupt) due to a high level of disturbances (Koch, 2001). Calm and protected areas with a broad reed belt (e.g., the test site Karpfenwinkel and the south-eastern part
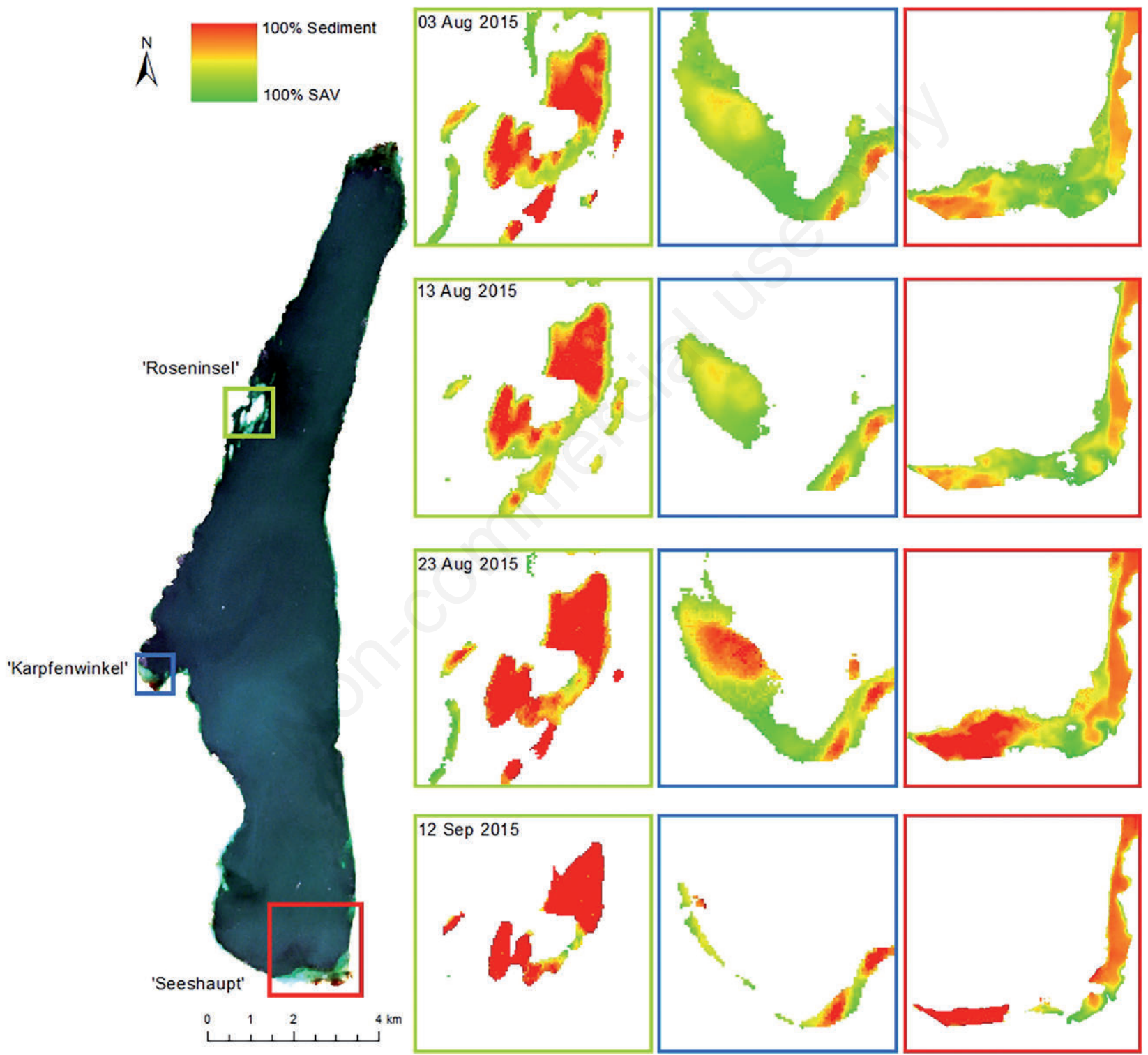

Fig. 7. Littoral bottom coverage of the investigated shallow water areas at Lake Starnberg illustrated after linear spectral unmixing using the bio-optical model WASI-2D on 3 August 2015, 13 August 2015, 23 August 2015 and 12 September 2015 (Sentinel-2A truecolour composite R-G-B: 665 nm-560 nm-490 nm, acquisition date: 3 August 2015; left). The boxes represent the investigated shallow water areas from left to right: 'Roseninsel' (green box), 'Karpfenwinkel' (blue box) and 'Seeshaupt' (red box). The result of 2 bottom types displays $100 \%$ bare sediment areas in red and $100 \%$ dense vegetated areas in green, mixed areas in yellow. Land and deep water areas are masked. 
of test site Seeshaupt) allow the development of a dense SAV patch. Areas with mixed coverage are characteristic for detritus overlay on sediment, plant residuals, epiphytes or sparsely growing SAV with sediment influence (Armstrong, 1993; Fyfe, 2003; Williams et al., 2003; Silva et al., 2008; Wolf et al., 2013).

The results indicate that two-bottom type approach (sediment and SAV classes) is able to support regular in situ mappings as recommended by the WFD. Independent of the SAV growth class, changes in the SAV spatial extend, e.g., the covering of previously ungrown areas or the desolation of vegetated areas, can be determined. This information further supports a systematic and costeffective planning of in situ mapping.

Changes in the SAV growth extend, e.g., the covering of previously ungrown areas or the punctually

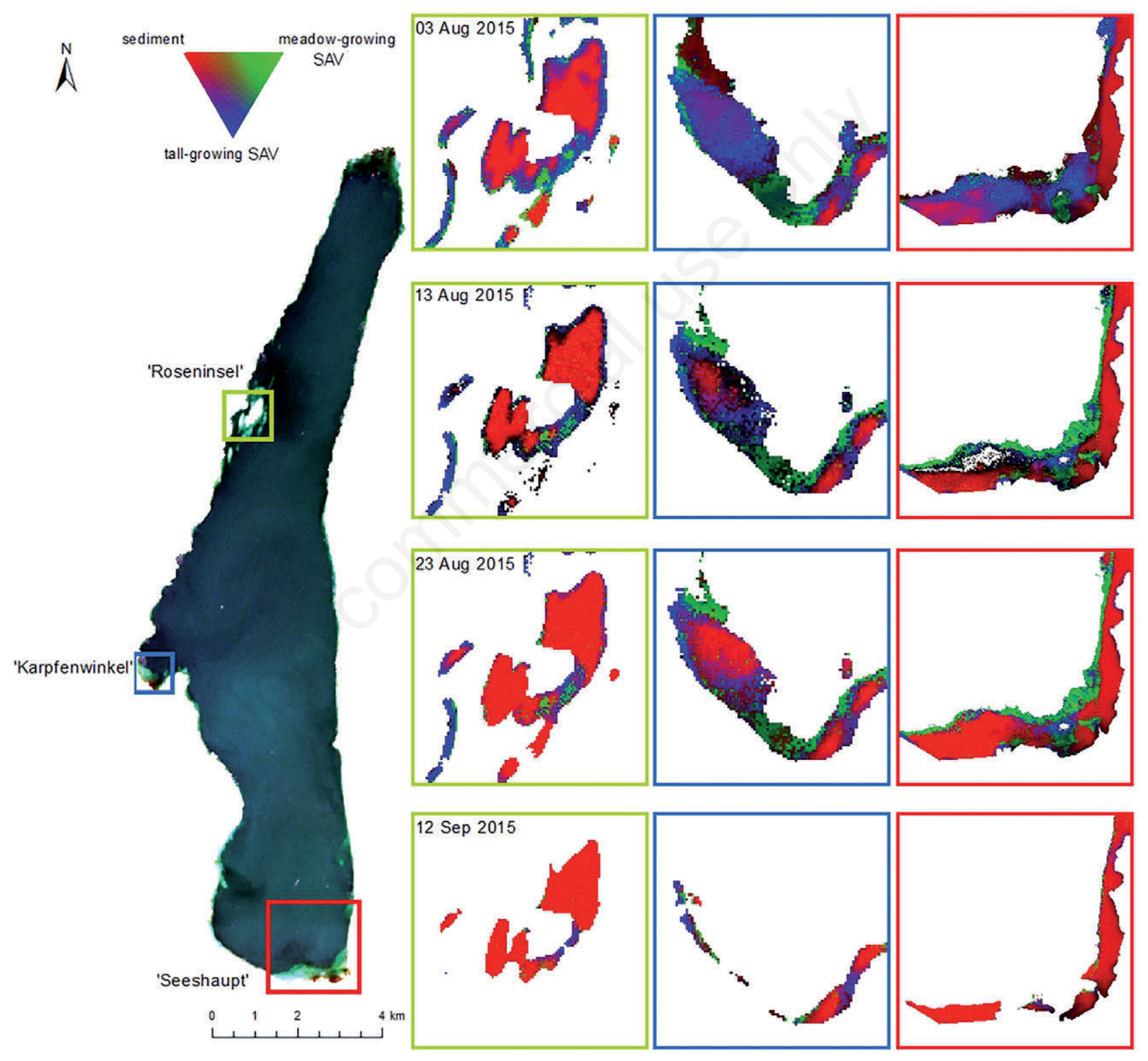

Fig. 8. Littoral bottom coverage of the investigated shallow water areas at Lake Starnberg illustrated after linear spectral unmixing using the bio-optical model WASI-2D on 3 August 2015, 13 August 2015, 23 August 2015 and 12 September 2015 (Sentinel-2A truecolour composite R-G-B: $665 \mathrm{~nm}-560 \mathrm{~nm}-490 \mathrm{~nm}$, acquisition date: 3 August 2015; left). The boxes represent the investigated shallow water areas from left to right: 'Roseninsel' (green box), 'Karpfenwinkel' (blue box) and 'Seeshaupt' (red box). The result of 3 bottom types displays areas of bare sediment (red), meadow-growing plant SAV classes (green) and tall-growing plant SAV classes (blue). Land and deep water areas are masked. 
desertification of vegetated areas, can be determined, independent of the growth type of SAV. This information allows a systematic use of divers and in situ investigations and supports the regular monitoring with regard to time and financial aspects.

\section{Seasonal spectral variation within the growing season}

In our study, we investigated on a period in late summer, where SAV is expected to change significantly with maximum plant height and patch extension in August (main vegetation time) to degrading and dying SAV patches in September. Modelled SAV reflectance spectra, resampled to Sentinel-2A, showed significant differences within the growing season (Fig. 4), which were sufficiently high to track the SAV class specific development during the monitoring period. Sentinel-2A therefore seems to be suitable for the differentiation between tall- and meadow-growing SAV, especially in the range of band $4(665 \mathrm{~nm})$ and $5(705 \mathrm{~nm})$, which are sensitive to chlorophyll-a variations.

At the end of the growing season in September, the spectral shape of meadow-growing SAV class is flattened in the yellow and orange wavelength region $(560 \mathrm{~nm}-$ $630 \mathrm{~nm}$ ); moreover, the chlorophyll-a absorption maximum is less distinct. This is due to variations in leaf pigment ratio (Sims and Gamon, 2002; Wolf et al., 2013), when a lower Chlorophyll-a content in ageing leaves unmasks other leaf pigments (e.g., carotenoids) and
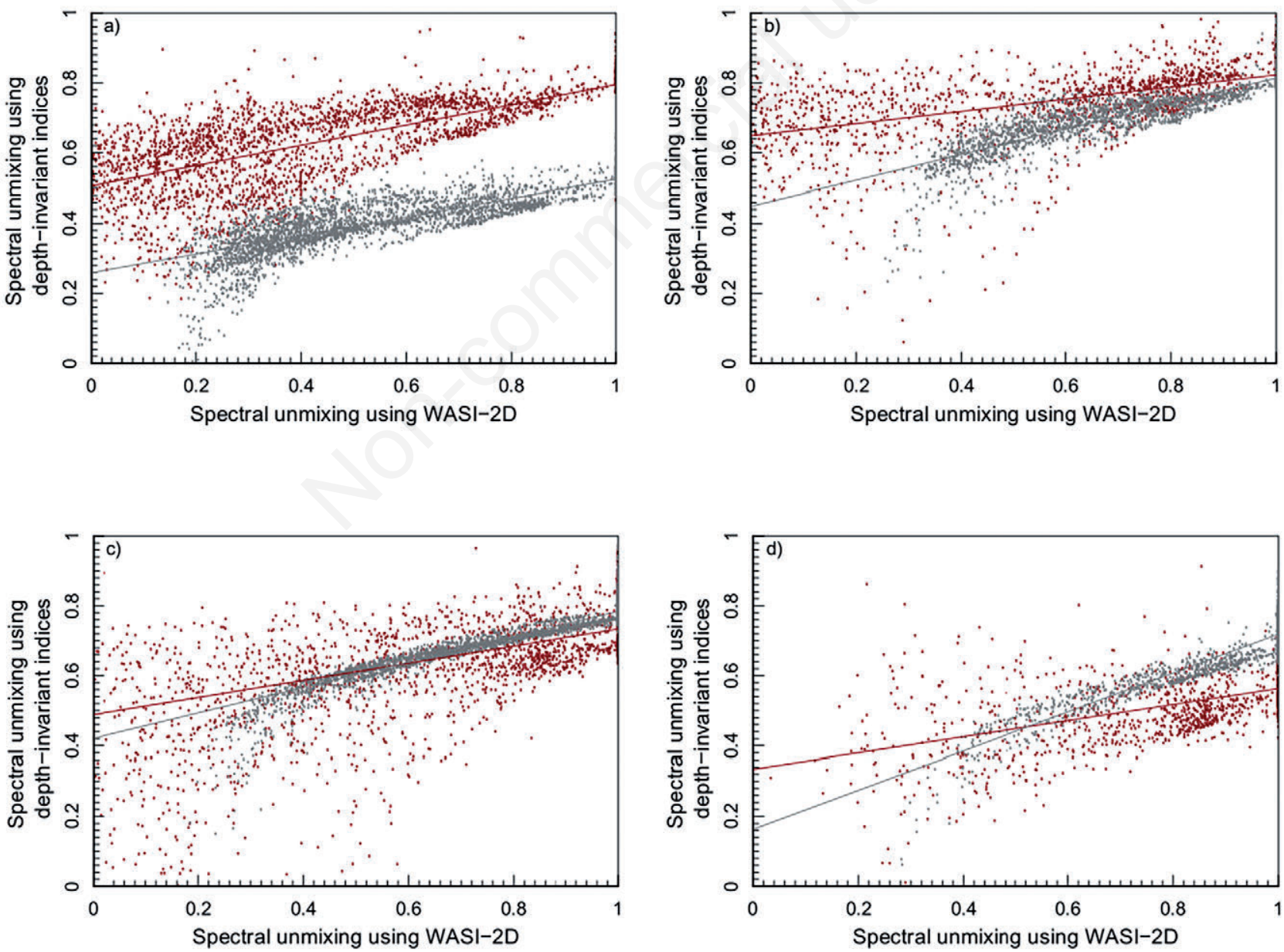

Fig. 9. Scatterplot with regression line of sediment for the acquisition dates 03 August 2015 (a), 13 August 2015 (b), 23 August 2015 (c) and 12 September 2015 (d). Results of spectral unmixing of 2 bottom types for sediment (grey) and results of the spectral unmixing of 3 bottom types for sediment (red). 
induces a shift towards yellow and orange wavelengths (Gitelson and Merzlyak, 1994; Sims and Gamon, 2002).

For a classification on SAV growth class level based on real Sentinel-2 data, a spectral unmixing was applied. Modelled spectra of the three littoral bottom types served as endmembers, whereas the SAV spectra were selected according to their phenologic status. The spatially distinct differentiation between sediment patches and areas of talland meadow-growing SAV classes (Figs. 6 and 8, Tabs. 3 and 5) suggests that Sentinel-2 data offer a suitable basis for a littoral bottom classification. The shallow water area near the harbour Seeshaupt is highly disturbed and therefore classified as sediment. Calm water regions and deeper water zones allow a dense SAV coverage (e.g., test site Karpfenwinkel and south-eastern part of test site Seeshaupt). The distribution of different SAV classes seemed to be dependent on the water depth. While tallgrowing SAV predominates in deeper water regions, meadow-growing SAV populates shallower areas close to the shoreline. Differing growth height and plant structure may explain this distribution detected by remote sensing data. The characteristic spectral response of tall-growing SAV classes dominates the reflectance signal in the deeper zones. In the Sentinel-2 data only the canopy of the tallgrowing SAV classes is apparent: they cover the lower growing SAV classes and therefore superimpose their characteristic reflectance signal. This finding may explain existing differences in classification results of remote
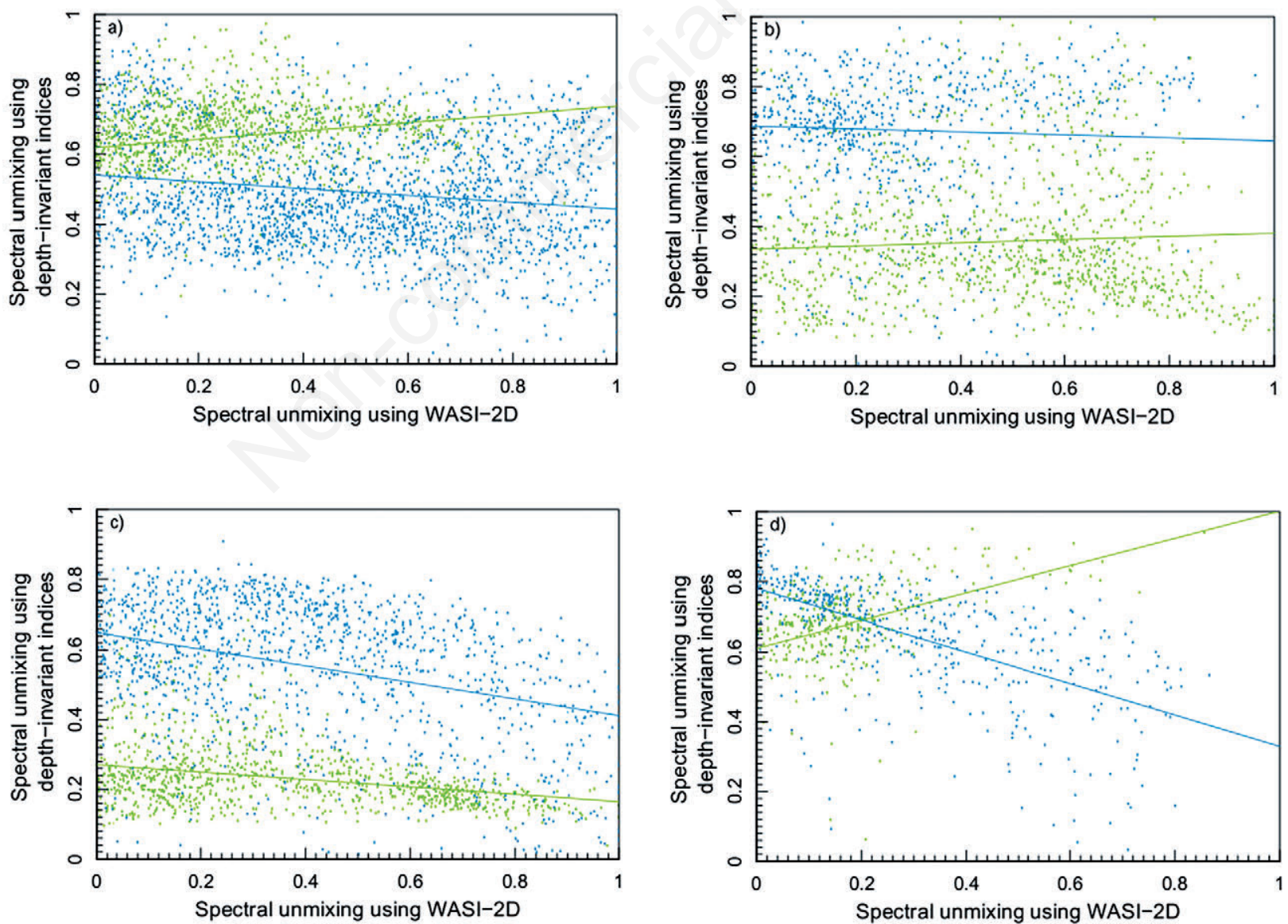

Fig. 10. Scatterplot with regression line of the different bottom types for the acquisition dates 03 August 2015 (a), 13 August 2015 (b), 23 August 2015 (c) and 12 September 2015 (d). Results of the spectral unmixing of 3 bottom types for meadow-growing SAV classes (green) and tall-growing SAV classes (blue). 
sensing data and diver mappings (Fig. 1). In the shallow water regions, meadow-growing SAV dominate the remote sensing signal, because low water levels aggravate growth of tall-growing SAV classes, which therefore are unable to develop a dense cover. This modifies the characteristic spectral signature and hinders a mapping based on remote sensing.

Data of 12 September have to be considered separately, because large parts of the shallow water area were masked wrongly as deep water. The performance of $R I$ highly depends on a homogenous deep water reflectance in red wavelengths $(630 \mathrm{~nm}-700 \mathrm{~nm})$. Differing water constituent concentrations at this acquisition date (see Tab. 1) therefore may have affected the $R I$ calculation. Improving automatic shallow water delineation may avoid such misinterpretation. Nevertheless, the spectral unmixing of three bottom types using depth-invariant indices also shows some irregularities for this acquisition date. The unmixing results are fundamentally different to those of pervious acquisition dates, which is probably due to an insufficient consideration of the water constituent concentration in the depth-invariant index calculation.

Comparing the results of both investigated methods showed similarities as well as differences between the spectral unmixing of two or three littoral bottom types (Figs. 9 and 10). For both methods, the results for sediment (Fig. 9) scatter less than for SAV classes (Fig. 10); sediment further showed higher $\mathrm{R}^{2}$ values (Tab. 6). This can be attributed to the spectral differences that are more distinct between sediment and SAV than between SAV growth classes. For both methods, low coefficients of determination demonstrate that an unmixing at SAV class growth level seems infeasible so far. To improve the results, we therefore recommend detailed in situ investigations to understand how the spectral signal of SAV species changes with their phenologic development.

When comparing the investigated methods, they offer specific advantages and disadvantages based on their methodology. The in situ measured input spectra of the reflectance models serve as a basis for both approaches. WASI-2D advantageously uses the input spectra without water influence directly for modelling above water reflectance $\left(R_{r s}^{0+}\right)$. Achieving a similar level with the depthinvariant indices approach necessitates several steps: each index is calculated on subsurface level, which includes a subsequent transformation to the level of satellite data, i.e., above water reflectance $\left(R_{r s}^{0+}\right)$. This additional but necessary step is a source of error, which can be avoided when using WASI-2D, since the modelling happens on the same level as the satellite data. The approach using WASI2D further has fewer processing steps and is therefore less time-consuming. Moreover, the physically based approach of WASI-2D directly includes the attenuation by water constituents on the above water reflectance. This influence therefore can be considered as spatially variable during modelling. In contrast, the depth-invariant index addresses the water column based on a spatially constant $K_{d}(\lambda)$ measurement. Additionally, WASI-2D can consider sun glint during modelling (Dörnhöfer et al., 2016), which is ignored by depth-invariant indices.

An advantage of the approach using the depth-invariant index is the option of focusing only on individual band combinations, which may omit band combinations with few information. Furthermore, the water depth is calculated from in situ measurements of $K_{d}(\lambda)$ while WASI-2D models the water depth as a fit parameter. These fit parameters (in this case water depth and fractional contribution from bottom reflectance) vary during modelling within a predefined range until modelled and satellite $R_{r s}^{0+}$ match a similarity criterion. The model results therefore are a highly probable combination of fit parameters, which, however, does not necessarily reflect reality. Other parameter combinations may therefore lead to a similar result, i.e. the inversion of a model may lead to spectral ambiguity. Modelling is further constrained by the number of available and suitable bands to avoid overfitting.

Besides the choice of the method, a major shortcoming of our study is the lack of validation data. For a meaningful validation, however, large-scale in situ measurements on SAV species level would be beneficial. Our study showed, that the currently available information based on transect mappings is insufficient for a solid validation of remote sensing data. We expect that large-scale mappings would be more promising to record extent and coverage of SAV patches, ideally during a Sentinel-2A overpass.

Furthermore, we expect that access to spectral information of sensors such as Sentinel-2 within the entire growing season may significantly improve the accuracy of a remote sensing based SAV monitoring. For this however, knowledge of species-specific variations within a growing season is essential. The setup of a spectral database of SAV species integrating both species-specific spectral characteristics and phenologic development is necessary to achieve a successful classification on SAV class level. Multi-year time-series further provides an insight in trends of SAV coverage and SAV class distribution. The revisit time and the high spatial resolution of Sentinel-2A may support the in situ SAV mappings as required by the WFD.

\section{CONCLUSIONS}

This study used four Sentinel-2A scenes of August and September 2015 to map the spatio-temporal development of SAV in shallow water areas of the oligotrophic Lake 
Starnberg (Southern Germany). To map sediment and SAV distribution as well as distribution on SAV class growth level, we applied the semi-empirical method of depth-invariant indices and the bio-optical model WASI2D. To provide endmember spectra for the monitoring period, we applied spectral reflectance models of different SAV types for different phenologic stages. The results confirm other studies demonstrating that the spatial and spectral resolution of Sentinel-2A data is suitable for SAV monitoring. Both applied methods provide similar spatial distributions of sediment and SAV. None of the methods, however, was able to show a clear distinction between meadow- and tall-growing SAV. The improvement of the validation of unmixing results seems solely possible by extensive in situ mappings carried out simultaneously to the satellite overpasses. We further recommend setting up a spectral database of SAV species at different phenologic stages, because an integration of SAV endmember spectra at the proper growth stage proved to enhance discrimination of SAV on class and species level. In view of global warming, a multi-year time-series may obtain information about trends in SAV coverage and species distribution. Satellite systems with high spatial resolution and a frequent revisit time such as Sentinel-2 offer the potential to support in situ SAV mappings as required by the WFD.

\section{ACKNOWLEDGMENTS}

This work was supported by the German Research Foundation (DFG) and the Technical University of Munich within the funding programme Open Access Publishing. The research of this study was funded by the Federal Ministry for Economic Affairs and Energy (BMWi) under the grant number 50EE1336 and 50EE1340 within the project LAKESAT. We would like to thank our colleagues at the Limnological Research Station Iffeldorf for their support in fieldwork. We thank the anonymous reviewers for their effort and helpful comments improving the manuscript.

\section{REFERENCES}

Armstrong RA, 1993. Remote sensing of submerged vegetation canopies for biomass estimation. Int. J. Remote Sens. 14:621-627.

Bavarian Environmental Agency, 2000. Digital elevation model of Lake Starnberg. BEA, Augsburg.

Bavarian Environmental Agency, 2018. Bavarian Hydrological Service. Accessed on: 30 June 2018. Available from: http://www.gkd.bayern.de

Brooks C, Grimm A, Shuchman R, Sayers M, Jessee N, 2015. A satellite-based multi-temporal assessment of the extent of nuisance Cladophora and related submerged aquatic vegetation for the Laurentian Great Lakes. Remote Sens. Environ.157:58-71.

Ciraolo G, Cox E, La Loggia G, Maltese A, 2006. The classification of submerged vegetation using hyperspectral MIVIS data. Ann. Geophys-Italy 49:287-294.

Dekker AG, Vos RJ, Peters SWM, 2002. Analytical algorithms for lake water TSM estimation for retrospective analyses of $\mathrm{TM}$ and SPOT sensor data. International Journal of Remote Sensing 23:15-35.

Dekker AG, Phinn SR, Anstee J, Bissett P, Brando VE, Casey B, Fearns P, Hedley J, Klonowski W, Lee ZP, 2011. Intercomparison of shallow water bathymetry, hydro-optics, and benthos mapping techniques in Australian and Caribbean coastal environments. Limnol. Oceanogr. Methods 9:396-425.

Dörnhöfer K, Göritz A, Gege P, Pflug B, Oppelt N, 2016. Water constituents and water depth retrieval from Sentinel-2A - A first evaluation in an oligotrophic lake. Remote Sens. 8:941.

Dörnhöfer K, Klinger P, Heege T, Oppelt N, 2018. Multi-sensor satellite and in situ monitoring of phytoplankton development in a eutrophic-mesotrophic lake. Sci. Total Environ. 612:1200-1214.

European Commission, 2000. Directive 2000/60/EC of the European Parliament and of the Council of 23 October 2000 establishing A framework for community action in the field of water policy. Official Journal, L 327/1, 22/12/2000, pp. 72.

Fritz C, Doernhoefer K, Schneider T, Geist J, Oppelt N, 2017 a. Mapping submerged aquatic vegetation using RapidEye satellite data: the example of Lake Kummerow (Germany). Water 9:510.

Fritz C, Schneider T, Geist J, 2017b. Seasonal variation in spectral response of submerged aquatic macrophytes: A case study at Lake Starnberg (Germany). Water 9:527.

Fyfe S, 2003. Spatial and temporal variation in spectral reflectance: Are seagrass species spectrally distinct? Limnol. Oceanogr. 48:464-479.

Gausman HW, 1984. Evaluation of factors causing reflectance differences between Sun and Shade Leaves. Remote Sens. Environ. 15:177-181.

Gege P, 2014. WASI-2D: A software tool for regionally optimized analysis of imaging spectrometer data from deep and shallow waters. Computers Geosci. 62:208-215.

George DG, 1997. The airborne remote sensing of phytoplankton chlorophyll in the lakes and tarns of the English Lake District. Int. J. Remote Sens. 18:1961-1975.

Giardino C, Bartoli M, Candiani G, Bresciani M, Pellegrini L, 2007. Recent changes in macrophyte colonisation patterns: an imaging spectrometry-based evaluation of southern Lake Garda (northern Italy). J. Appl. Remote Sens. 1:011509.

Giardino C, Brando VE, Dekker AG, Strömbeck N, Candiani G, 2007. Assessment of water quality in Lake Garda (Italy) using Hyperion. Remote Sens. Environ. 109:183-195.

Giardino C, Bresciani M, Valentini E, Gasperini L, Bolpagni R, Brando VE, 2015. Airborne hyperspectral data to assess suspended particulate matter and aquatic vegetation in a shallow and turbid lake. Remote Sens. Environ. 157:48-57.

Giardino C, Candiani G, Bresciani M, Lee Z, Gagliano S, Pepe M, 2012. BOMBER: A tool for estimating water quality and bottom properties from remote sensing images. Computers Geosci. 45:313-318. 
Gitelson A, Merzlyak MN, 1994. Quantitative estimation of chlorophyll-a using reflectance spectra: Experiments with autumn chestnut and maple leaves. J. Photochem. Photobiol. B 22:247-252.

Gitelson AA, Zur Y, Chivkunova OB, Merzlyak MN, 2002. Assessing carotenoid content in plant leaves with reflectance spectroscopy. Photochem. Photobiol. 75:272-281.

Heblinski J, Schmieder K, Heege T, Agyemang TK, Sayadyan H, Vardanyan L, 2011. High-resolution satellite remote sensing of littoral vegetation of Lake Sevan (Armenia) as a basis for monitoring and assessment. Hydrobiologia 661:97-111.

Heege T, Fischer J, 2004. Mapping of water constituents in Lake Constance using multispectral airborne scanner data and a physically based processing scheme. Can. J. Remote Sens. 30:77-86.

Heege T, Kiselev V, Wettle M, Hung NN, 2014. Operational multi-sensor monitoring of turbidity for the entire Mekong Delta. Int. J. Remote Sens. 35:2910-2926.

Koch EW, 2001. Beyond light: physical, geological, and geochemical parameters as possible submersed aquatic vegetation habitat requirements. Estuaries 24:1-17.

Kohler A, 1978. [Methoden der Kartierung von Flora und Vegetation von Süßwasserbiotopen].[Article in German]. Landschaft Stadt 10:73-85.

Lee Z, Carder KL, Mobley CD, Steward RG, Patch JS, 1998. Hyperspectral remote sensing for shallow waters. I. A semianalytical model. Appl. Opt. 37:6329-6338.

Lee Z, Carder KL, Mobley CD, Steward RG, Patch JS, 1999. Hyperspectral remote sensing for shallow waters: 2 . Deriving bottom depths and water properties by optimization. Appl. Opt. 38:3831-3843.

Lee Z, Casey B, Arnone RA, Weidemann AD, Parsons R, Montes MJ, Gao BC, Goode W, Davis CO, Dye J, 2007. Water and bottom properties of coastal environment derived from Hyperion data measured from the EO-1 spacecraft platform. J. Appl. Remote Sensi.1:011502

Lyzenga DR, 1978. Passive remote sensing techniques for mapping water depth and bottom features. Appl. Opt. 17:379-383.

Lyzenga DR, 1981. Remote sensing of bottom reflectance and water attenuation parameters in shallow water using aircraft and Landsat data. Int. J. Remote Sens. 2:71-82.

Malthus TJ, George DG, 1997. Airborne remote sensing of macrophytes in Cefni Reservoir, Anglesey, UK. Aquat. Bot. 58:317-332.

Manessa MDM, Kanno A, Sekine M, Ampou EE, Widagti N, As-syakur AR, 2014. Shallow-water benthic identification using multispectral satellite imagery: investigation on the effects of improving noise correction method and spectral cover. Remote Sensing 6:4454-4472.

Maritorena S, 1996. Remote sensing of the water attenuation in coral reefs: a case study in French Polynesia. Int. J. Remote Sens. 17:155-166.

Melzer A, 1999. Aquatic macrophytes as tools for lake management. Hydrobiologia 395:181-190.

Melzer A, Zimmermann S, Schorer A. 2003. [Seelitorale in Bayern: Starnberger See, Makrophyten-Kartierungen 1979, 1989 und 2000].[Book in German]. Bayerisches Landesamt für Wasserwirtschaft: $112 \mathrm{pp}$.

Palmer SCJ, Kutser T, Hunter PD, 2015. Remote sensing of inland waters: Challenges, progress and future directions. Remote Sens. Environ. 157:1-8.

Penning WE, Dudley B, Mjelde M, Hellsten S, Hanganu J, Kolada A, van den Berg M, Poikane S, Phillips G, Willby N, Ecke F, 2008. Using aquatic macrophyte community indices to define the ecological status of European lakes. Aquat. Ecol. 42:253-264.

Pinnel N, Heege T, Zimmermann S, 2004. Spectral discrimination of submerged macrophytes in lakes using hyperspectral remote sensing data. SPIE Proceedings on Ocean Optics XVII 1:1-16.

Poikane S, Birk S, Böhmer J, Carvalho L, de Hoyos C, Gassner H, Hellsten S, Kelly M, Lyche Solheim A, Olin M, Pall K, Phillips G, Portielje R, Ritterbusch D, Sandin L, Schartau A-K, Solimini AG, van den Berg M, Wolfram G, van de Bund W, 2015. A hitchhiker's guide to European lake ecological assessment and intercalibration. Ecol. Indicators 52:533-544.

R Core Team, 2017. R: A language and environment for statistical computing. R Foundation for Statistical Computing, Vienna. Available from: http://www.R-project.org/

Roessler S, Wolf P, Schneider T, Melzer A, 2013a. Multispectral remote sensing of invasive aquatic plants using RapidEye, p. 109-123. In: J.M. Krisp, L. Meng, R. Pail and U. Stilla (eds.), Earth Observation of Global Changes (EOGC). Springer, Berlin.

Roessler S, Wolf P, Schneider T, Zimmermann S, Melzer A. 2013b. Water constituent retrieval and littoral bottom mapping using hyperspectral APEX imagery and submersed artificial surfaces. eProceedings EARSeL 12:44-57.

Rooney N, Kalff J, 2000. Inter-annual variation in submerged macrophyte community biomass and distribution: the influence of temperature and lake morphometry. Aquat. Bot. 68:321-335.

Short FT, Neckles HA, 1999. The effects of global climate change on seagrasses. Aquat. Bot. 63:169-196.

Shuchman RA, Sayers MJ, Brooks CN, 2013. Mapping and monitoring the extent of submerged aquatic vegetation in the Laurentian Great Lakes with multi-scale satellite remote sensing. J. Great Lakes Res. 39:(S1):78-89.

Silva TSF, Costa MPF, Melack JM, Novo EMLM, 2008. Remote sensing of aquatic vegetation: theory and applications. Environ. Monit. Assess. 140:131-145.

Sims DA, Gamon JA, 2002. Relationships between leaf pigment content and spectral reflectance across a wide range of species, leaf structures and developmental stages. Remote Sens. Environ. 81:337-354.

Skubinna JP, Coon TG, Batterson TR, 1995. Increased abundance and depth of submersed macrophytes in response to decreased turbidity in Saginaw Bay, Lake Huron. J. Great Lakes Res. 21:476-488.

Søndergaard M, Johansson LS, Lauridsen TL, Jørgensen TB, Liboriussen L, Jeppesen E, 2010. Submerged macrophytes as indicators of the ecological quality of lakes. Freshwater Biol. 55:893-908.

Spitzer D, Dirks RWJ, 1987. Bottom influence on the reflectance of the sea. Int. J. Remote Sens. 8:279-308.

TriOS, 2018. RAMSES spectroradiometer. Accessed on: 30 June 2018. Available from: http://www.trios.de/en/products/ sensors/ramses.html 
Williams DJ, Rybicki NB, Lombana AV, O’Brien TM, Gomez RB, 2003. Preliminary investigation of submerged aquatic vegetation mapping using hyperspectral remote sensing. Environ. Monit. Assess. 81:383-392.

Wöbbecke K, Klett G, Rechenberg B, 2003. [Wasserbeschaffenheit der wichtigsten Seen in der Bundesrepublik Deutschland: Datensammlung 1981-2000].[Book in German] Umweltbundesamt, Dessau-Roßlau: $167 \mathrm{pp}$.

Wolf P, Rößler S, Schneider T, Melzer A, 2013. Collecting in situ remote sensing reflectances of submersed macrophytes to build up a spectral library for lake monitoring. Eur. J. Remote Sens. 46:401-416.

WWA Weilheim, 2015. [Makrophytenkartierung und WRRLGewässerzustandsmonitoring im Starnberger See]. Data set request at WWA Weilheim.

Yuan L, Zhang L-Q, 2008. Mapping large-scale distribution of submerged aquatic vegetation coverage using remote sensing. Ecol. Inform. 3:245-251. 